\title{
Advances in $\mathrm{Pb}$-free Solder Microstructure Control and Interconnect Design
}

\author{
Kathlene N. Reeve, John R. Holaday, Stephanie M. Choquette, Iver E. Anderson, and Carol A. Handwerker
}

(Submitted April 13, 2016; in revised form May 20, 2016; published online June 9, 2016)

\begin{abstract}
New electronics applications demanding enhanced performance and higher operating temperatures have led to continued research in the field of $\mathrm{Pb}$-free solder designs and interconnect solutions. In this paper, recent advances in the microstructural design of $\mathrm{Pb}$-free solders and interconnect systems were discussed by highlighting two topics: increasing $\beta$-Sn nucleation in Snbased solders, and isothermally solidified interconnects using transient liquid phases. Issues in $\beta$ Sn nucleation in Sn-based solders were summarized in the context of Swenson's 2007 review of the topic. Recent advancements in the areas of alloy composition manipulation, nucleating heterogeneities, and rapid solidification were discussed, and a proposal based on a multi-faceted solidification approach involving the promotion of constitutional undercooling and nucleating heterogeneities was outlined for future research. The second half of the paper analyzed two different approaches to liquid phase diffusion bonding as a replacement for high-Pb solders, one based on the application of the pseudo-binary $\mathrm{Cu}-\mathrm{Ni}$-Sn ternary system, and the other on a proposed thermodynamic framework for identifying potential ternary alloys for liquid phase diffusion bonding. All of the concepts reviewed relied upon the fundamentals of thermodynamics, kinetics, and solidification, to which Jack Smith substantially contributed during his scientific career.
\end{abstract}

Keywords constitutional undercooling, grain nucleation, liquid phase diffusion bonding, Pb-free solder, ternary diagrams, transient liquid

\section{Introduction}

Through a scientific career spanning more than 50 years (1953-2007), Dr. Jack Smith was intrigued by investigations that linked thermochemistry with the constitution and crystal structures of metals, compounds, and alloy systems. His analyses of the thermodynamics of binary, ternary, and multi-component systems were coupled with detailed evaluations of the elastic constants of a wide range of multicomponent materials, ranging from binary lithium alloys to yttria stabilized zirconia. ${ }^{[1,2]}$ Fortunately, Jack Smith was still at the top of his game and up for new challenges in the early 1990s when one of our co-authors (IEA) sought his collaboration on the mapping and verification of a previously undiscovered ternary eutectic reaction in the $\mathrm{Sn}-\mathrm{Ag}-\mathrm{Cu}$ system. Using a classic thermodynamics approach, Jack's guidance on review of the literature and possible interpretation of the limited data set from previous

Kathlene N. Reeve, John R. Holaday, and Carol A. Handwerker, Purdue University, 701 West Stadium Ave., West Lafayette, IN 47907, USA; Stephanie M. Choquette, and Iver E. Anderson, Ames Laboratory (USDOE), Iowa State University, Ames, IA 50011, USA; Stephanie M. Choquette, and Iver E. Anderson, Iowa State University, Ames, IA 50011, USA. Contact e-mail: klindley@purdue.edu. work were invaluable in their investigation of ternary eutectic behavior. ${ }^{[3]}$ Now, as we continue addressing challenges in the $\mathrm{Pb}$-free transition, in controlling the microstructure in circuit assembly solder joints and in developing high temperature solders to replace high- $\mathrm{Pb}$ solders for hierarchical assembly in multi-chip module applications, we have sought to channel the direction and wisdom of Jack Smith, employing the foundations of thermodynamics and phase equilibria to guide our analyses.

Today's electronics industry has transitioned to lead-free components in consumer electronic devices due to the known risks of lead to human health. The Waste Electrical and Electronic Equipment (WEEE) directive, enacted by the European Union (EU) in 2006, requires all consumer products being sold within the EU to be $\mathrm{Pb}$-free. ${ }^{[4]}$ This legislation is also supported by the Restriction of Hazardous Substances (RoHS) directive, which restricts the use of several other hazardous materials, including $\mathrm{Pb}^{[5,6]}$ Since the electronics industry supplies a global marketplace, compliance with EU regulations has driven the transition toward a more restricted set of materials in consumer products regardless of where they are sold, particularly for solder alloys used in circuit board assembly and packaging. ${ }^{[7]}$ At the same time, new devices and applications are demanding higher performance solder alloys for assembly than currently exist, leading to continuing research in new $\mathrm{Pb}$-free alloys and interconnect solutions that meet these enhanced performance challenges. Furthermore, the transition to $\mathrm{Pb}$-free electronics is not yet complete: the RoHS exemptions for high- $\mathrm{Pb}$, high-temperature alloys used in wafer bumping, substrate bumping, and die attach will likely continue until a practical replacement becomes available. There are no drop-in, $\mathrm{Pb}$-free solders which have 
solidus temperatures in the 260 to $310{ }^{\circ} \mathrm{C}$ range that can substitute for high- $\mathrm{Pb}$ solders. Based on an examination of the binary phase diagrams with one low melting point element $\left(T_{\mathrm{m}}<400{ }^{\circ} \mathrm{C}\right)$, or a low temperature eutectic, and our experience with designing $\mathrm{Pb}$-free alloys to replace the $\mathrm{Sn}-\mathrm{Pb}$ eutectic, it is unlikely such a solder is possible.

From the point of view of processing temperatures, the challenges in developing both a high performance $\mathrm{Pb}$-free solder alloy for circuit board assembly and a high temperature $\mathrm{Pb}$-free solder or alternative interconnect solution for wafer bumping, substrate bumping, and die attach can be illustrated by examining the use of the $\mathrm{Sn}-\mathrm{Pb}$ system. Traditionally, solder alloys in both application regimes were composed of binary $\mathrm{Sn}-\mathrm{Pb}$ alloy combinations. These alloys had many useful properties, including forming a simple binary eutectic, excellent mechanical properties and thermomechanical fatigue resistance, good electrical conductivity, excellent wetting characteristics, and a classic eutectic solidification morphology with two primary solid solution phases. The large solid solubility of $\mathrm{Sn}$ in $\mathrm{Pb}$ (18.9 wt.\% at $183^{\circ} \mathrm{C}$ ) leads to a range of useful solidus temperatures from $183{ }^{\circ} \mathrm{C}$ to close to the melting point of $\mathrm{Pb}\left(327^{\circ} \mathrm{C}\right)$, and a tunable "mushy" (liquid + solid) zone width based on alloy composition. Soldering is first performed at the chip or die attach level with high- $\mathrm{Pb}(\mathrm{Pb}-\mathrm{Sn})$ solders with a high solidus temperature and narrow mushy zone. A standard high temperature solder composition of $\mathrm{Pb}-\mathrm{Sn}$ is $95 \mathrm{~Pb}-5 \mathrm{Sn}$ (wt.\%), with a solidus temperature of $320^{\circ} \mathrm{C}$. Once solidified, packaged components are soldered onto circuit boards without melting the die attach level solder by using the $\mathrm{Sn}-\mathrm{Pb}$ eutectic composition of $62.13 \mathrm{Sn}-37.87 \mathrm{~Pb}$ (wt.\%), with its eutectic temperature of $183{ }^{\circ} \mathrm{C} .^{[8-10]}$

The microelectronics community has developed a range of $\mathrm{Pb}$-free solder alloys for various circuit board assembly applications. Tin-based $\mathrm{Pb}$-free alloys, most notably $\mathrm{Sn}-\mathrm{Ag}-$ $\mathrm{Cu}$ (SAC) near-eutectic alloys, discovered by the team that included Jack Smith, ${ }^{[3]}$ have become widely used as an alternative for eutectic $\mathrm{Sn}-\mathrm{Pb}$ due to tin's affordability, environmental passivity, low toxicity, and compatibility with existing microelectronic components and assembly practice. The SAC eutectic composition is $95.6 \mathrm{Sn}-3.5 \mathrm{Ag}-$ $0.9 \mathrm{Cu}$ wt. $\%$, with a eutectic temperature of $217^{\circ} \mathrm{C} .^{[11]} \mathrm{A}$ projection of the SAC liquidus surface is shown in Fig. 1(a). After about 20 years of extensive use, the SAC solder alloys have proven to be a reasonable substitute for $\mathrm{Sn}-\mathrm{Pb}$, but still have problems in some types of assembly operations, e.g., ball grid arrays, and more importantly, in terms of their reliability with respect to thermal fatigue and impact resistance. Interestingly, all of these problems can be traced to the well-known difficulty in the nucleation of Sn, i.e., in controlling the as-reflowed joint microstructure. This lack of microstructure control has motivated significant research on the effects of minor alloy additions to SAC or other binary Sn-based alloys on $\mathrm{Sn}$ nucleation over a number of years. ${ }^{[12-}$ ${ }^{20]}$ In contrast to circuit board assembly solders in which many high-Sn alloys are available commercially, Au-based eutectics (Au-Sn, Au-Si, Au-Ge) are the dominant $\mathrm{Pb}$-free alloys used for high-temperature soldering applications, but

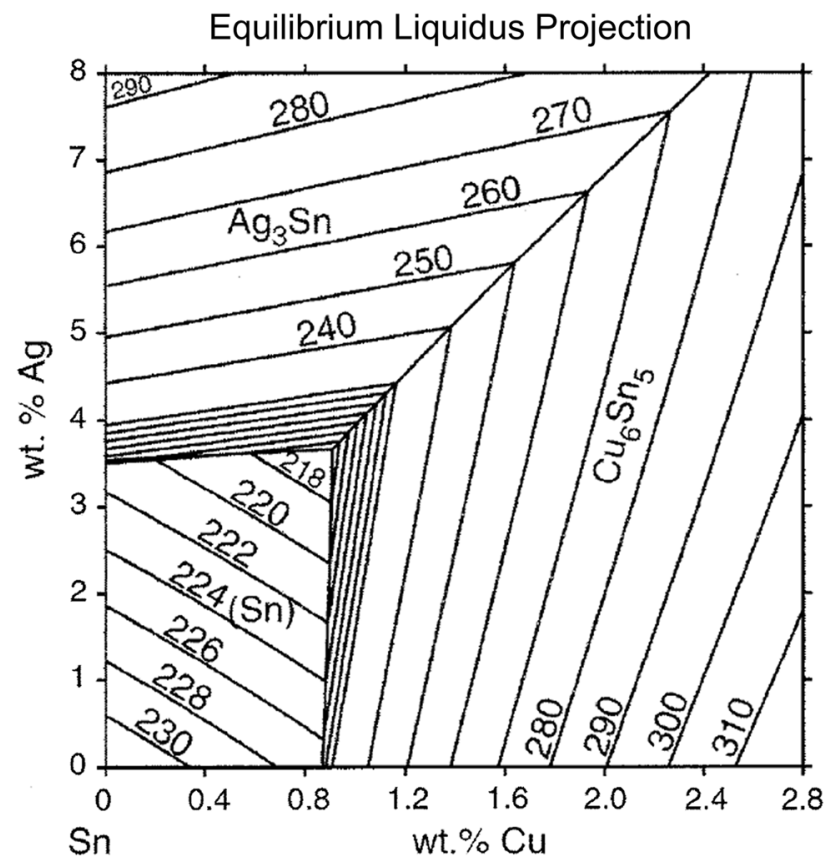

(a)

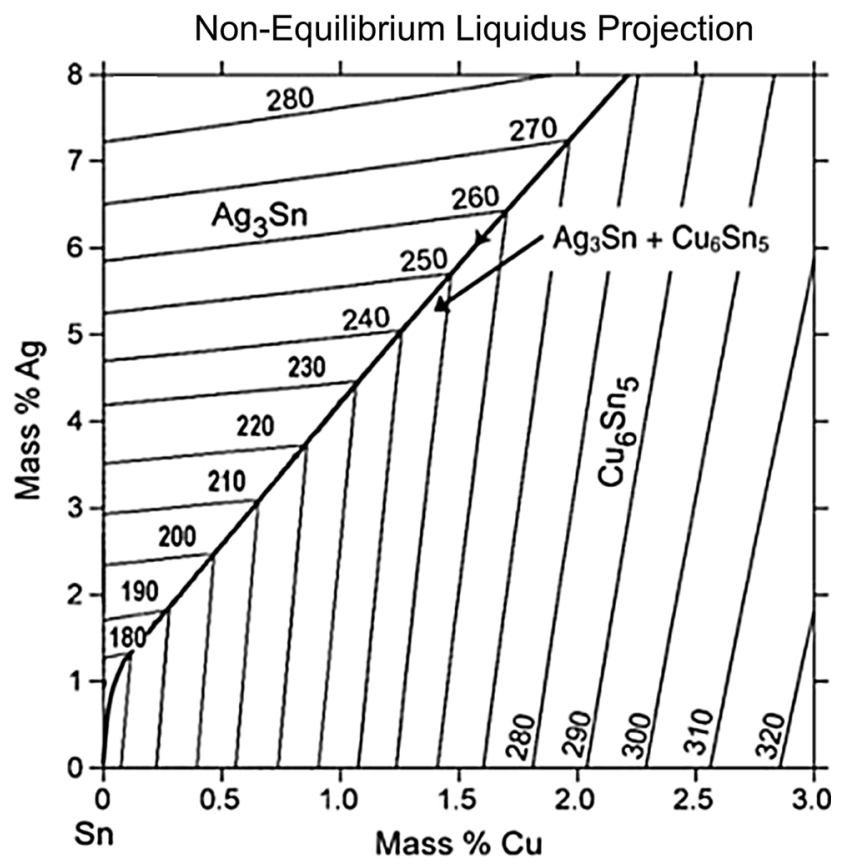

(b)

Fig. 1 Two differing projections of the liquidus surface of the Sn-Ag-Cu ternary system. In (a), the calculated equilibrium liquidus surface is shown from Ref 11, and (b) a non-equilibrium projection of the liquidus surface is displayed, showing the extended primary intermetallic phase formations in the system during eutectic undercooling ${ }^{[21]}$ 
at significantly higher cost than high- $\mathrm{Pb}, \mathrm{Pb}-\mathrm{Sn}$ alloys. Considered together, this explains the great $\mathrm{R} \& \mathrm{D}$ race to develop both higher performing $\mathrm{Pb}$-free solder alloys for circuit board assembly, as well as new approaches or concepts for widespread high temperature assembly and applications.

The goal of this article is to provide a review of two approaches to designing higher performance solder alloys and interconnect systems: (1) strategies to increase $\beta$-Sn nucleation in Sn-based solder alloys and (2) liquid phase diffusion bonding (LPDB) to create high temperature, high reliability, $\mathrm{Pb}$-free interconnects. Both of these topics are highly active research areas in today's $\mathrm{Pb}$-free solder community and both research areas rest foundationally on concepts in thermodynamics and phase equilibria, the kinetics of intermetallic formation, and principles of alloy solidification. The first half of this article reviews current research in $\beta$-Sn nucleation based on the work published since Swenson's seminal 2007 review on the difficulties in nucleating $\beta$-Sn in Sn-based solders. ${ }^{[21]}$ The second half of this review focuses on the challenges in designing multicomponent LPDB alloys with controlled microstructures as replacements for high- $\mathrm{Pb}$, high temperature solders.

\section{2. $\beta$-Sn Nucleation in Tin-Based Solders}

As noted by Swenson in his 2007 review, the solidification of $\beta$-Sn occurs by heterogeneous nucleation and has been difficult to induce or predict, with undercoolings as large as $15-40{ }^{\circ} \mathrm{C}$ in Sn-based solder alloys, and as large as $187^{\circ} \mathrm{C}$ in surface passivated Sn droplets. ${ }^{[21,22]}$ These large undercoolings can permit extended formation of primary intermetallic compounds (IMCs) far from thermodynamic equilibrium. This results in large, highly anisotropic solder IMCs, such as $\mathrm{Cu}_{6} \mathrm{Sn}_{5}, \mathrm{Ag}_{3} \mathrm{Sn}$, and both $\mathrm{Cu}_{6} \mathrm{Sn}_{5}$ and $\mathrm{Ag}_{3} \mathrm{Sn}$ during solidification of $\mathrm{Sn}-\mathrm{Cu}, \mathrm{Sn}-\mathrm{Ag}$, and SAC alloys, respectively. The eventual nucleation and subsequent rapid growth of $\beta$-Sn dendrites then follows, resulting in large $\beta$ Sn dendrite/grain sizes that frequently exhibit common twinning misorientations. ${ }^{[23,24]}$

It is this non-equilibrium, extended proeutectic formation of phases, such as the formation of large, primary $\mathrm{Ag}_{3} \mathrm{Sn}$ blades in SAC alloys, which has dictated the need for improved impact ("drop shock") resistance in Sn-based solders. Song et al. performed a telling study on the vibrational fracture properties of SAC solder alloys in 2007, just after the release of Swenson's review article. ${ }^{[25]}$ The study elucidated the role of $\mathrm{Ag}_{3} \mathrm{Sn}$ in reducing the ductility and vibrational dampening of SAC alloys, both of which are important properties for high reliability applications in the aerospace and automotive industries. In particular, acicular eutectic $\mathrm{Ag}_{3} \mathrm{Sn}$ and large, proeutectic $\mathrm{Ag}_{3} \mathrm{Sn}$ blades were shown to dramatically reduce solder ductility and adversely affect the vibrational performance of the SAC solder alloys by providing preferred pathways for accelerated crack growth. ${ }^{[25]}$ By enhancing the nucleation of the $\beta$-Sn phase during solder alloy solidification, proeutectic formation of $\mathrm{Ag}_{3} \mathrm{Sn}$ and metastable $\mathrm{Ag}_{3} \mathrm{Sn}$ far below the eutectic temperature can be avoided, leading to improved mechanical properties.

In addition to the $\beta$-Sn nucleation issues, the $\beta$-Sn phase itself is known to exhibit large elastic and thermal expansion anisotropies due to its body-centered tetragonal (BCT) crystal structure. Thus, the behavior of individual joints, such as the thermal fatigue tolerance and resistance to electromigration and creep, are all linked to the size, orientation, and morphology of the $\beta-\mathrm{Sn}$ dendrites within Sn-based solder joints. ${ }^{[26]}$ It is due to $\beta$-Sn's anisotropic properties that microstructural non-uniformity joint-to-joint and the resulting variability in mechanical properties of Snbased solder microstructures can be a large issue. ${ }^{[26,27]}$ The ability to understand, control, and increase heterogeneous nucleation of the $\beta$-Sn phase is, therefore, needed to create more reproducible solder microstructures with improved thermomechanical properties for the high reliability, high performance $\mathrm{Pb}$-free solder alloys that are needed in the microelectronics industry today.

\subsection{Swenson's 2007 Review of $\beta$-Sn Nucleation}

In 2007, Swenson reviewed the issues linked to the difficulty in the nucleation of the $\beta$-Sn phase in Sn-based solders. ${ }^{[21]}$ Swenson offered three potential approaches/tactics to alleviate the $\beta$-Sn nucleation issue based on concepts guided by fundamental thermodynamics and kinetics, with the goal of avoiding the large, proeutectic formation of solder IMCs and formation of a few large $\beta$-Sn grains during solidification.

The first approach outlined by Swenson was to employ the use of non-equilibrium phase diagrams to inform decisions of alloy composition in order to minimize proeutectic IMC formations in the as-solidified solder microstructures. Swenson illustrated this strategy through the use of non-equilibrium SAC ternary liquidus surface projections, such as the diagram show in Fig. 1(b). It was suggested that, if the expected average undercooling is known, an alloy composition could be chosen to avoid the formation of primary phases. For example, if the average undercooling at which one would expect $\beta$-Sn nucleation is approximately $15^{\circ} \mathrm{C}$, then the $\mathrm{Ag}$ content in the alloy should be reduced to a point at which the $\mathrm{Ag}_{3} \mathrm{Sn}$ IMC phase liquidus surface is at least $15^{\circ} \mathrm{C}$ below the equilibrium $\mathrm{SAC}$ eutectic temperature, thus avoiding primary $\mathrm{Ag}_{3} \mathrm{Sn}$ formation completely. Effectively, this suggestion attacks one of the issues of delayed $\beta$-Sn nucleation, primary IMC phase growth, but it fails to address the enhancement of $\beta-\mathrm{Sn}$ nucleation itself.

The second approach was to introduce $\beta$-Sn solidification catalysts to enhance the nucleation of the $\beta$-Sn phase, thus reducing eutectic undercooling. The addition of $\mathrm{Zn}$ was reviewed, where it is noted that micro-alloying additions of $\mathrm{Zn}$ (0.1 wt.\% additions to $\mathrm{Sn}-3.4 \mathrm{Ag}-0.9 \mathrm{Cu}$ wt.\% alloys) reduced the $\beta$-Sn eutectic undercooling in $\mathrm{SAC}+\mathrm{Zn}$ alloys and suppressed large $\mathrm{Ag}_{3} \mathrm{Sn}$ IMC blade formations within the alloy microstructures, suggesting enhanced $\beta$-Sn nucleation. ${ }^{[28,29]}$ Inoculation of $\beta-S n$, either from micro-alloying additions or from secondary phases, is a promising approach, although an attributable mechanism for the success of such 
micro-alloying additions in the inoculation of the Sn-liquid alloy has been notably absent from the literature.

Finally, Swenson suggested the use of rapid solidification to avoid formation of large primary IMC particles. Rapid solidification would be expected to reduce, if not completely eliminate, primary IMC phase formation via the reduction of time spent in the liquid state during solidification before $\beta$ Sn nucleation occurs. Swenson presented results from rapid solidification experiments that showed IMC refinement, but $\beta$-Sn grain dendrite size and misorientation were shown to be unaffected. ${ }^{[30,31]}$ The employment of rapid solidification techniques to modify and reduce the formation of IMC phases from liquid melts is a proven process, and one that can be leveraged to improve Sn-based solders. It is vital to not only establish techniques for enhancing nucleation of $\beta$ $\mathrm{Sn}$ and controlling $\beta$-Sn grain size within as-solidified solders, but to also understand how to maintain and control those effects throughout the course of the multiple reflow cycles that are often necessary for microelectronics manufacturing. In the sections that follow, research progress in exploiting each of Swenson's approaches in enhancing $\beta$-Sn nucleation is reviewed, as well as their implications for improved solder performance. Finally, suggestions for future progress in increasing $\beta$-Sn nucleation and controlling $\beta$-Sn grain size are outlined.

\subsection{Compositional Modifications to Tin-Based Alloys}

In accordance with Swenson's first approach in employing non-equilibrium phase diagrams to inform alloy compositional choices, as well as the poor impact and vibrational performance of SAC solders attributed to the presence of primary $\mathrm{Ag}_{3} \mathrm{Sn}$, alloy modifications primarily based on reductions in, or elimination of, $\mathrm{Ag}$ from $\mathrm{Sn}$-based alloys have been researched heavily within the solder community. Suh et al. studied the effects of reduced Ag content on the fracture resistance of SAC solders, where SAC105 (Sn-1.0Ag-0.5Cu wt.\%) and SAC405 (Sn-4.0Ag$0.5 \mathrm{Cu}$ wt.\%) were compared via drop impact testing. ${ }^{[32]}$ The results of the study found that the SAC105 alloy displayed superior drop impact resistance due to the increased bulk compliance and high plastic energy dissipation of the alloy microstructure. This result was linked to the reduced Ag content of the alloy, and thus the reduced formation of primary $\mathrm{Ag}_{3} \mathrm{Sn}$, as well as the increased phase fraction of $\beta$ $\mathrm{Sn}$ and the relatively low elastic modulus of the $\beta-\mathrm{Sn}$ phase. ${ }^{[32]}$ Suh et al. discussed the effects of Ag content from a thermodynamic standpoint through the use of Fig. 2(a), where reductions in $\mathrm{Ag}$ are shown to alter the Sn-IMC tielines, thus increasing the phase fraction of $\beta-\mathrm{Sn}$ with decreased Ag content, in agreement with Swenson's description of such techniques. Figure 2(b) displays the results of the drop impact testing of the SAC105 and SAC405 alloys. A greater than 10x enhancement of the number of drops to joint failure was realized for SAC105 as compared to SAC405. ${ }^{[32]}$

In addition to the reduction of Ag content, the reliability and mechanical performance of Sn-based solder alloys that completely eliminate Ag from the alloy design have also been examined. Tsukamoto et al. performed a thorough study of Ni-doped and non-Ni-doped $\mathrm{Sn}-\mathrm{Cu}(\mathrm{SC}), \mathrm{SAC}$, and $\mathrm{Sn}-\mathrm{Pb}$ solder ball grid array (BGA) joint systems via the use of high-speed shear impacting testing. ${ }^{[33]}$ The testing showed that the $\mathrm{SC}+\mathrm{Ni}$ solder BGAs out-performed all other alloy compositions in shear impact testing. The SAC solder BGAs were found to have the least resistance to shear impact testing, with cracking initiating at the IMC interfacial bond layer and brittle failure of the solder joints. The
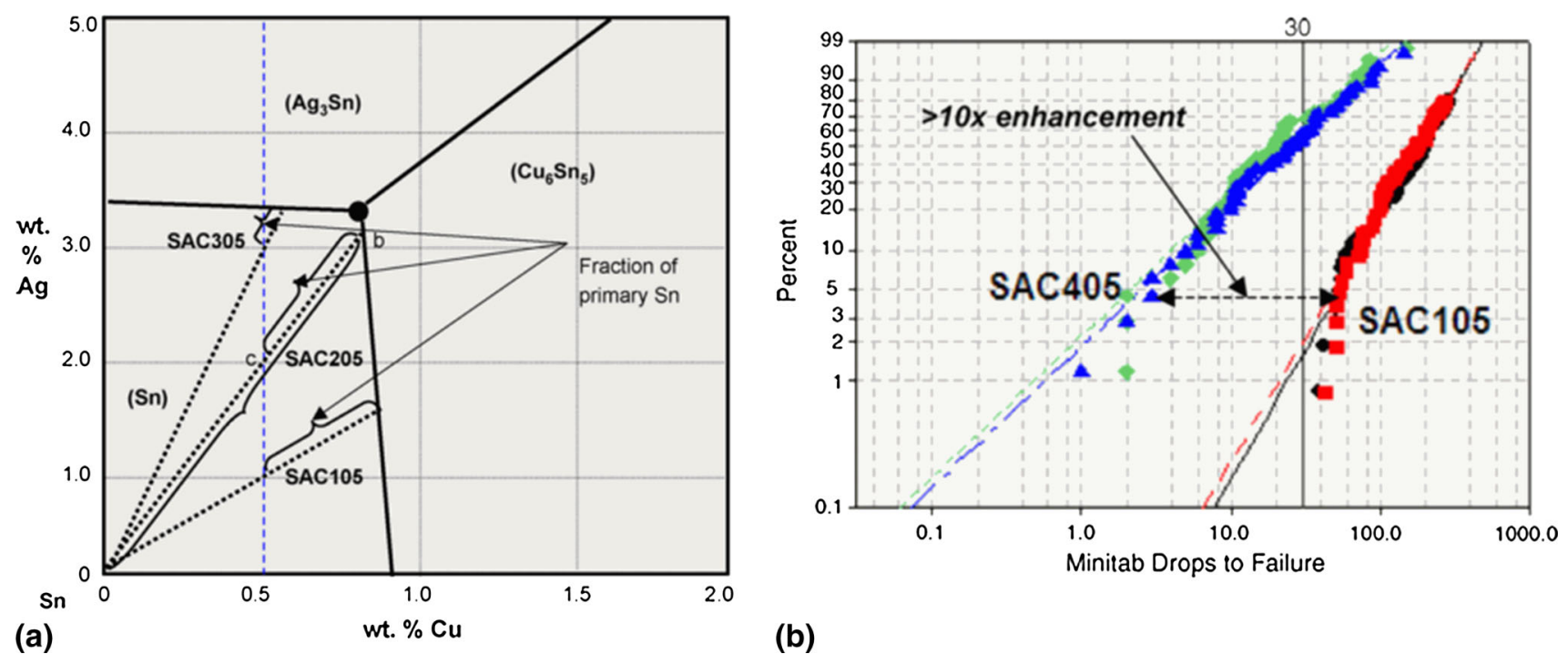

(b)

Fig. 2 (a) A schematic of the SAC ternary phase space in the Sn-rich corner. The effect of reduced Ag content is portrayed via the increased phase fraction of the $\beta$-Sn phase, as seen by the tie-line representation. (b) The drop impact testing results of the study, where the superior performance of the SAC105 (Sn-1.0Ag-0.5Cu wt.\%) alloy over the SAC405 (Sn-4.0Ag- $0.5 \mathrm{Cu}$ wt.\%) alloy can be seen ${ }^{[32]}$ (Color figure available online) 
addition of Ni to the SC alloy was found to "smooth" the morphology of the interfacial $\mathrm{Cu}_{6} \mathrm{Sn}_{5}$ layer between the solder BGA and the bonded pad. ${ }^{[33]}$ These results agreed well with research that has been conducted in the area of Ni-doped $\mathrm{Cu}-{ }_{6} \mathrm{Sn}_{5}$ by a number of different research groups. ${ }^{[34-40]}$ The research has documented the strong cross-interaction of $\mathrm{Cu}$ and $\mathrm{Ni}$ in solder joints. Typically, $\mathrm{Ni}$ is observed to substitute on the $\mathrm{Cu}_{6} \mathrm{Sn}_{5}$ IMC lattice for $\mathrm{Cu}$ atoms, thus creating $(\mathrm{Cu}, \mathrm{Ni})_{6} \mathrm{Sn}_{5}$, which enhances the impact resistance of the solder IMC interfacial layer by stabilizing the hexagonal form of $\mathrm{Cu}_{6} \mathrm{Sn}_{5}(\eta)$ down to room temperature, negating its transition to the monoclinic structure $\left(\eta^{\prime}\right)$ at $186{ }^{\circ} \mathrm{C}$. The de-stabilization of this crystallographic transformation by $\mathrm{Ni}$ additions avoids the volume change that accompanies the transition of unalloyed $\mathrm{Cu}_{6} \mathrm{Sn}_{5}$ IMC phase with reductions in temperature, a transformation that can lead to cracking in the phase. ${ }^{[37-40]} \mathrm{Ni}$ additions were also shown to enhance the planarization of solder IMC $\left(\mathrm{Cu}_{3} \mathrm{Sn}\right.$ and $(\mathrm{Cu}$, $\mathrm{Ni})_{6} \mathrm{Sn}_{5}$ ) interfacial layers, and the cross-interaction of $\mathrm{Cu}$ and $\mathrm{Ni}$ has been shown to reduce the thickness of the $\mathrm{Cu}_{3} \mathrm{Sn}$ IMC layer during thermal aging. ${ }^{[33,35]}$

\subsection{Inoculation of Tin-Based Alloys}

Micro-alloying additions to SAC and SC solder alloys has been an active research area for the past $10-15$ years. ${ }^{[12-20]}$ Anderson and co-workers have examined a wide range of additions to SAC alloys; Al (0.05 wt.\%), Zn ( $\geq 0.21$ wt.\%), and $\mathrm{Mn}(\geq 0.1 \mathrm{wt} . \%)$ were each found to reduce $\beta$-Sn undercoolings to $2-4{ }^{\circ} \mathrm{C}$, and to reduce, or eliminate, the formation of $\mathrm{Ag}_{3} \mathrm{Sn}$ proeutectic blades. The early studies were not able to identify the cause of the observed benefits from the micro-alloying additions, but did state that the specific micro-alloying additions were chosen because of their substitutional solubility in $\mathrm{Cu}$ and with the goal of enhanced nucleation of primary $\mathrm{Cu}_{6} \mathrm{Sn}_{5}$ from which the $\beta-\mathrm{Sn}$ could then nucleate. ${ }^{[17]}$ However, if such a nucleation mechanism were to exist between $\mathrm{Cu}_{6} \mathrm{Sn}_{5}$ and $\beta$-Sn, it is likely that researchers would have confirmed it, given the presence of $\mathrm{Cu}_{6} \mathrm{Sn}_{5}$ in majority of solder alloys and solder joints.

Based on the micro-alloying research performed on Snbased solders to date, micro-alloying additions of $\mathrm{Al}$ appear to be promising. Boesenberg et al. reported the suppression of the $\mathrm{Ag}_{3} \mathrm{Sn}$ blade phase at $\mathrm{Al}$ contents greater than 0.05 wt. $\%$, but less than $0.20 \mathrm{wt} . \%$, and reductions in $\beta$-Sn undercooling of $\sim 50 \%$ at $\mathrm{Al}$ concentrations 0.25 wt. $\%$ within SAC+Al solder alloys. Finally, Boesenberg et al. described the formation of $\mathrm{Cu}-\mathrm{Al}$ IMC particles within the Al-modified SAC solder samples, which were identified via XRD measurements as the $\mathrm{Cu}_{33} \mathrm{Al}_{17}$ phase. The $\mathrm{Cu}_{33} \mathrm{Al}_{17}$ particles were found to be buoyant within the liquid-Sn, floating to the top of the examined solder joints during solder reflow, and the $\mathrm{Cu}_{33} \mathrm{Al}_{17} \mathrm{IMC}$ displayed particularly high hardness values $(49.1 \pm 2.5 \mathrm{GPa})$ via nanoindentation measurements. ${ }^{[18]}$ Reeve et al. then surveyed the addition of $\mathrm{Al}$ to various $\mathrm{SAC}$ and $\mathrm{SC}$ alloys, where the volume fraction of the $\mathrm{Cu}_{\mathrm{x}} \mathrm{Al}_{\mathrm{y}}$ phase was shown to vary dependently with the $\mathrm{Al}$ concentration in the alloy, as expected, and the solidification temperature of the $\mathrm{Cu}_{\mathrm{x}} \mathrm{Al}_{\mathrm{y}}$ phase was identified at $450-550{ }^{\circ} \mathrm{C} .{ }^{[20]}$

Xian et al. have identified the preferred orientation relationship between $\mathrm{Cu}_{6} \mathrm{Sn}_{5}$ and both $\mathrm{Cu}_{33} \mathrm{Al}_{17}$ and $\mathrm{Cu}_{9} \mathrm{Al}_{4}$.

$$
(1 \overline{2} 10)_{\mathrm{Cu}_{6} \mathrm{Sn}_{5}} \|(10 \overline{1})_{\mathrm{Cu}_{x} \mathrm{Al}_{y}} \text { and }[0001]_{\mathrm{Cu}_{6} \mathrm{Sn}_{5}} \|[111]_{\mathrm{Cu}_{x} \mathrm{Al}_{y}}
$$

The $\mathrm{Cu}_{x} \mathrm{Al}_{y}$ particles were shown by Xian et al. to provide nucleating surfaces for the $\mathrm{Cu}_{6} \mathrm{Sn}_{5}$ particles within $\mathrm{SC}+\mathrm{Al}$ alloys, reducing the overall undercooling and size of the $\mathrm{Cu}_{6} \mathrm{Sn}_{5}$ particles in the systems. ${ }^{[41,42]}$ Similar results have been obtained by Reeve et al. over a wide range of cooling rates. ${ }^{[20,43,44]}$ This orientation relationship between the $\mathrm{Cu}_{x} \mathrm{Al}_{y}$ and $\mathrm{Cu}_{6} \mathrm{Sn}_{5}$ has important implications to solder microstructural control due to the high temperature stability $\left(450-550{ }^{\circ} \mathrm{C}\right)$ of the $\mathrm{Cu}_{x} \mathrm{Al}_{y}$ phase. If the $\mathrm{Cu}_{x} \mathrm{Al}_{y}$ phase can be uniformly distributed throughout the solder matrix, then during reflow cycling of the solder, the $\mathrm{Cu}_{x} \mathrm{Al}_{y}$ phase will remain solid in the alloy melt. This high temperature stability of the $\mathrm{Cu}_{\mathrm{x}} \mathrm{Al}_{\mathrm{y}}$ phase would then provide preferred and persistent heterogeneous nucleation sites for $\mathrm{Cu}_{6} \mathrm{Sn}_{5}$ during each solidification cycle and an added level of control over the formation of the $\mathrm{Cu}_{6} \mathrm{Sn}_{5}$ phase. Figure 3(a-f) displays various examples of the epitaxial relationship between the $\mathrm{Cu}_{\mathrm{x}} \mathrm{Al}_{\mathrm{y}}$ phases and the $\mathrm{Cu}_{6} \mathrm{Sn}_{5}$ phase within a range of $\mathrm{SAC}+\mathrm{Al}$ and $\mathrm{SC}+\mathrm{Al}$ alloy compositions. ${ }^{[20,41,43]}$ Additionally, Sweatman et al. performed a grain refinement survey of various micro-alloying additions to pure $\mathrm{Sn} .{ }^{[19]}$ The study surveyed several possible grain refining additions to pure $\mathrm{Sn}$, and noted that additions of $\mathrm{Zn}, \mathrm{Mg}$, and $\mathrm{Al}$ all refined the as-cast grain size of the $\mathrm{Sn}+\mathrm{X}$ castings. The addition of Al displayed the strongest grain refinement both within the as-cast and recrystallized states at additions of 0.3 and $0.5 \mathrm{wt} . \% \mathrm{Al}$ to pure Sn castings. These results indicate a possible link between $\mathrm{Al}$ additions, reduced $\beta$-Sn undercooling observed within the Al-modified alloys, and possible enhanced nucleation of the $\beta$-Sn phase. ${ }^{[19]}$

Finally, Belyakov and Gourlay have examined heterogeneous nucleation of $\beta$-Sn from $\mathrm{XSn}_{4}$ type IMC, including $\mathrm{PtSn}_{4}, \mathrm{PdSn}_{4}$, and $\mathrm{NiSn}_{4}{ }^{[45]}$ The introduction of $\mathrm{XSn}_{4}$ type IMCs, either present as a primary phase or as an interfacial IMC layer, was shown to significantly reduce the undercooling of the $\beta-S n$ phase within the Sn-X alloys. Undercoolings within the alloys were reduced to $3-4{ }^{\circ} \mathrm{C}$, as compared to pure $\mathrm{Sn}$ undercoolings measured at $\sim 35^{\circ} \mathrm{C}$ within the study. The orientation relationship between the $\beta$ Sn phase and the $\mathrm{XSn}_{4}$ IMCs was identified as:

$$
(100)_{\beta-\mathrm{Sn}} \|(008)_{\mathrm{XSn}_{4}} \text { and }[001]_{\beta-\mathrm{Sn}} \|[100]_{\mathrm{XSn}_{4}}
$$

Despite the potent catalysis of $\beta$-Sn by the $\mathrm{XSn}_{4} \mathrm{IMC}$, it was noted that the $\beta$-Sn grain size remained large and unaffected by the presence of the catalytic IMC. Belyakov and Gourlay made note of this and remarked on the need for a combination of effective heterogeneous nucleation sites for $\beta-\mathrm{Sn}$, such as $\mathrm{XSn}_{4}$, and constitutional undercooling within the liquid-Sn to promote grain refinement of the $\beta-\mathrm{Sn}$ phase. $^{[45]}$ 

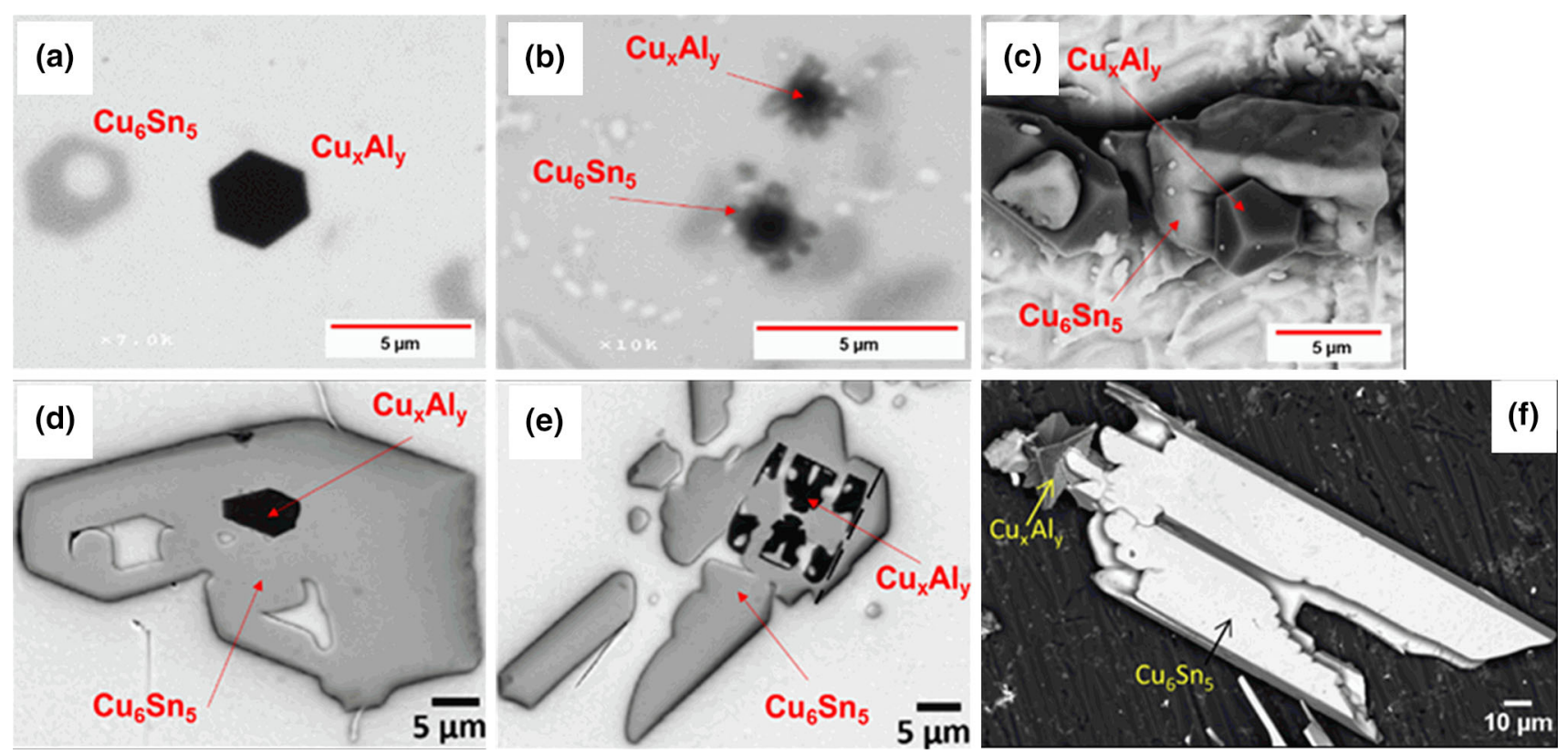

Fig. 3 Various depictions of the epitaxial relationship between $\mathrm{Cu}_{6} \mathrm{Sn}_{5}$ and $\mathrm{Cu}_{\mathrm{x}} \mathrm{Al}_{\mathrm{y}} \mathrm{IMC}$ within $\mathrm{SAC}+\mathrm{Al}$ and $\mathrm{SC}+\mathrm{Al}$ alloys. Micrographs (a, b) were collected by the author from work in Ref 20, and (c) is from deep etching experimentation reported in Ref 43. Micrographs (d, f) were modified and complied from the work completed in Ref 41 (Color figure available online)

\subsection{Rapid Solidification of Tin-Based Alloys}

Of the suggestions made by Swenson in his review, less work has been completed in the area of rapid solidification of solder alloys. Reeve et al. recently completed a study of rapidly solidified $\mathrm{SC}+\mathrm{Al}$ alloys produced via drip atomization and melt spinning. ${ }^{[43,44]}$ The work considered three different $\mathrm{SC}+\mathrm{Al}$ alloy compositions, with $\mathrm{Al}$ contents ranging from 0.1 to $0.4 \mathrm{wt} . \%$, and cooling rate treatments spanning eight orders of magnitude. The work showed the refinement of the $\mathrm{Cu}_{\mathrm{x}} \mathrm{Al}_{\mathrm{y}}$ and $\mathrm{Cu}_{6} \mathrm{Sn}_{5} \mathrm{IMC}$ phases down to sub-micron ranges through the application of rapid solidification processing (RSP). Ideal initial solidification cooling rates within the range of $10^{3}-10^{4}{ }^{\circ} \mathrm{C} / \mathrm{s}$ (water quenching to drip atomization) were identified for realizing simultaneous IMC particle size refinement and a maintained $\mathrm{Cu}_{x} \mathrm{Al}_{y} /$ $\mathrm{Cu}_{6} \mathrm{Sn}_{5}$ epitaxial relationship during solidification. Figure $4 \mathrm{a}-\mathrm{b}$ displays the refinement of both IMC phases and the maintained nucleant relationship between the $\mathrm{Cu}_{x} \mathrm{Al}_{y}$ and $\mathrm{Cu}_{6} \mathrm{Sn}_{5}$ phases for $\mathrm{Sn}-1.41 \mathrm{Cu}-0.1 \mathrm{Al}$ wt.\% drip atomized alloy microstructures from the study ${ }^{[43]}$ Unfortunately there was no observed effect on the nucleation of $\beta-S n$ due to the employed rapid solidification methods.

A coarsening study was also performed by Reeve et al., after initial rapid solidification via drip atomization and melt spinning. After reflow cycling between 20 and $250{ }^{\circ} \mathrm{C}$ for $1-$ 5 cycles, both alloy samples displayed little-to-no coarsening of the $\mathrm{Cu}_{\mathrm{x}} \mathrm{Al}_{\mathrm{y}}$ phase, as compared to the initial assolidified microstructures. However, the $\mathrm{Cu}_{6} \mathrm{Sn}_{5}$ particle displayed coarsening behavior dependent on the temperature stability of the $\mathrm{Cu}_{6} \mathrm{Sn}_{5}$ in the alloy composition. Significant $\mathrm{Cu}_{6} \mathrm{Sn}_{5}$ particle coarsening occurred in the alloy composition where the $\mathrm{Cu}_{6} \mathrm{Sn}_{5}$ melted completely upon reflow to $250{ }^{\circ} \mathrm{C}$, but little coarsening of the $\mathrm{Cu}_{6} \mathrm{Sn}_{5}$ phase was observed for the alloy where only partial melting of the $\mathrm{Cu}_{6} \mathrm{Sn}_{5}$ phase occurred during reflow cycling to $250{ }^{\circ} \mathrm{C}$. The epitaxial relationship between the $\mathrm{Cu}_{x} \mathrm{Al}_{y}$ and $\mathrm{Cu}_{6} \mathrm{Sn}_{5}$ IMC was qualitatively maintained throughout the course of reflow cycling for both samples. These results show promise for the control of IMC formation within these Al-modified alloys, not only after initial solidification, but also throughout subsequent reflow cycling necessary for solder joint manufacturing. ${ }^{[44]}$

\subsection{Suggestions for Future Improvements in $\beta-S n$ Nucleation}

As summarized above, a great deal of work on enhancing the nucleation of $\beta$-Sn within Sn-based solders has been conducted since Swenson's 2007 review. Effective approaches in solder compositional variations to control IMC formation, identification of effective micro-alloying additions and heterogeneous inoculants for $\beta$-Sn, and techniques for rapid solidification of solder alloys have all contributed to the improvement of Sn-based solder joint microstructural control. However, a singular Sn-based alloy composition has yet to be identified that can holistically control: (1) solder IMC formation, (2) $\beta$-Sn undercooling, and (3) refinement of $\beta-\mathrm{Sn}$ grain size with multiple non-twinned orientations. As mentioned by Belyakov and Gourlay in their investigation of $\beta$-Sn inoculant IMC phases, ${ }^{[4]}$ a multi-faceted approach must be taken to solder alloy design to achieve both enhanced $\beta$-Sn nucleation and $\beta$-Sn grain size control, including:

1. alloying to promote constitutional undercooling in the Sn-liquid, and

2. introducing high temperature inoculant phase/s to pro- 

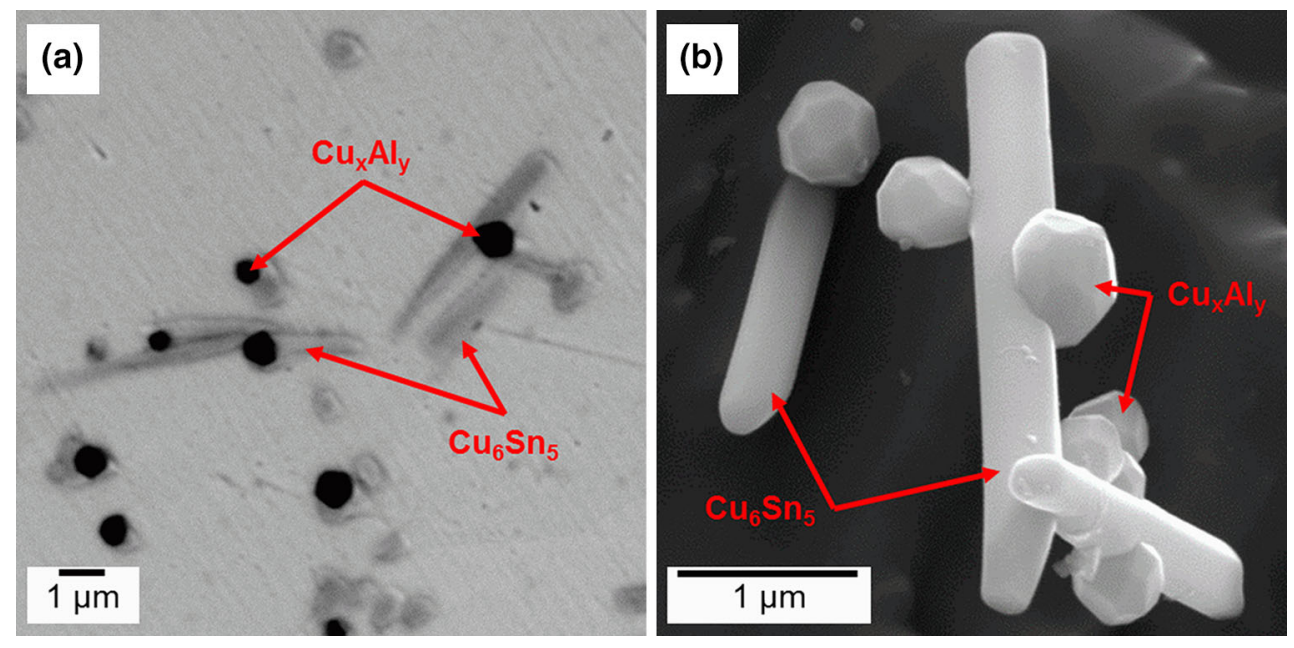

Fig. 4 (a) 2-dimensional polished cross-section and (b) 3-dimensonal deep etched sample, depicting the epitaxial relationship between $\mathrm{Cu}_{6} \mathrm{Sn}_{5}$ and $\mathrm{Cu}_{x} \mathrm{Al}_{y}$ IMC within a Sn-1.41Cu-0.1Al wt.\% drip atomized alloy (estimated cooling rate: $10^{4}{ }^{\circ} \mathrm{C} / \mathrm{s}$ ). (Previously unpublished micrographs provided by the author) (Color figure available online)

vide multiple, dispersed heterogeneous nucleation sites with specific activity for $\beta$-Sn during solidification.

The effects of constitutional undercooling on solid/liquid transformations in metallic systems have been described in classic works of Tiller, Jackson, Chalmers, and Kurz. ${ }^{[4-51]}$ StJohn et al. recently reviewed the current understanding of the effects of constitutional undercooling on nucleation and grain refinement in alloys. ${ }^{[52]}$ The process of constitutional undercooling occurs during solidification as solute is rejected from the solidifying phase, resulting in a concentration gradient of solute ahead of the solidification front and a modification to the local temperature of the adjacent liquid. Thus, every point ahead of the solidification front has a unique solute concentration and a corresponding liquidus temperature that is below that of the equilibrium liquidus temperature of the system, promoting local, compositionally dependent undercooling in the liquid ahead of the solidifying phase. Constitutional undercooling thus works to provide enhanced activation of nucleation sites directly ahead of the solidification front. The "growth restriction factor" (GRF) has been established as the most appropriate parameter for quantifying the effect of solute additions on restricting the growth of the solid interface in an undercooled liquid:

$\mathrm{GRF}=m_{\mathrm{L}} C_{0}(k-1)$

where $m_{\mathrm{L}}$ is the slope of the liquidus, $C_{0}$ is the alloy composition, and $k$ is the partition coefficient. A solute addition that results in a high GRF promotes a higher rate of development of constitutional undercooling in the liquid, slowing the advance of the solid interface into the undercooled liquid. This allows for more opportunity for nucleation events to activate ahead of the solidification front, and thus promotes grain refinement in the alloy. ${ }^{[52]}$
Seminal research by Easton and StJohn et al. in various systems, notably $\mathrm{Al}$ alloys, has shown that a high solute GRF correlates not only to enhanced constitutional undercooling, but also to reduction in the extent of the "nucleation free zone" (NFZ) that is typically established ahead of a growing solid-liquid interface. In particular, the combination of constitutional undercooling effects and the introduction of heterogeneous nucleant particles has been shown to enhance grain refinement in alloys. For example, the combination of inoculant nucleation surfaces $\left(\mathrm{TiB}_{2}\right)$ and excess solute in the melt (Ti) provides constitutional undercooling of the $\mathrm{Al}$ liquid, as well as potent $\mathrm{Al}$ heterogeneous nucleation sites. This two-step solidification approach results in an overall grain refinement effect in these $\mathrm{Al}$ alloy systems. ${ }^{[52-56]}$ Such an approach has yet to be applied to $\mathrm{Pb}$-free, $\mathrm{Sn}$-based solder alloys, but given the need for enhanced nucleation of the $\beta$-Sn phase and the need to decrease the $\beta$-Sn grain size in solder joints, employing multi-part solidification tactics in solder alloys offers much promise. Values of GRF for varying solute element concentrations to pure $\mathrm{Sn}$ can be used as a valuable guide in the selection of possible alloy systems to promote constitutional undercooling during $\beta$-Sn solidification. It should be noted, that although the GRF is appropriate to use in terms of down-selecting potential alloying elements that promote constitutional undercooling, it does not ultimately guarantee a grain refinement effect. As noted by Easton et al., grain refinement within an alloy will depend not only on the degree of constitutional undercooling corresponding to the chosen solute concentration, but also on the thermal profile in the liquid ahead of the solidification front, the distribution and potency of inoculant particles in the liquid, the rate of diffusion of the solute species in the liquid (solute accumulation between growing grains can significantly reduce constitutional undercooling), the evolution of latent heat upon solidification, and the flux of heat away from the solid-liquid interface. ${ }^{[52-54]}$ 
When considering GRFs to select potential solute additions to pure $\mathrm{Sn}$, it is noted that Sn-based alloys have generally low solute GRF values for various elemental additions in the $\mathrm{Sn}$ liquid at typical micro-alloying levels. Table I displays several solute options and their corresponding GRF values at their maximum solubility levels in the $\mathrm{Sn}$ liquid, as calculated from thermodynamic data gathered from ThermoCalc version 3, TCSLD3 solder alloy database. ${ }^{[57]}$ The table portrays the fact that, especially when compared to the micro-alloying addition of Ti solute to $\mathrm{Al}$ (GRF of 36.8 at $0.15 \mathrm{wt.}^{\left[{ }^{[53]}\right.}$ ), the GRF values of the various solute additions to the $\mathrm{Sn}$ liquid are considerably lower, specifically at low concentrations. The most promising options from the current list include the possibility of reaching higher values of GRF with increased alloying concentrations, for example, a GRF of 86 at $53 \mathrm{wt} \% \mathrm{Bi}$ and a value of 29 at $8 \mathrm{wt} . \% \mathrm{Zn}$. It is also interesting to note that the micro-alloying elements that are generally accepted as helping to reduce the undercooling of $\beta-\mathrm{Sn}$, such as $\mathrm{Mn}, \mathrm{Al}$, and Co, all have very low GRFs in the alloy liquid, signaling that any observed benefits in reduced undercooling within these systems must stem from a mechanism other than constitutional undercooling.

Despite some of these limitations, using GRF concepts to increase the grain refinement of $\beta$-Sn may still be possible by looking outside the typical range of micro-alloying additions. For example, Bi concentrations of 22 wt.\% would achieve a GRF value of 36 in the Sn-Bi liquid, reaching levels comparable to micro-alloying additions of Ti to Al. In addition to decreasing grain size, other microstructural factors influence the balance between the need for improved fatigue life and improved impact resistance in Sn-based solder joints. As summarized above, the generally poor impact resistance of SAC solder alloys can be improved by reducing $\mathrm{Ag}$ content in the alloy, thus reducing the formation of primary $\mathrm{Ag}_{3} \mathrm{Sn}$. This enhancement in impact resistance though, often comes at the price of decreased thermomechanical fatigue resistance due to decreased phase

Table I Liquidus slopes ( $m_{L}$, assumed linear), partition coefficients $(k)$, maximum concentrations of solutes in the $\mathrm{Sn}$-liquid, and corresponding solute $G R F$ values

\begin{tabular}{ccccc}
\hline Sn $+\mathbf{X}$ & $\begin{array}{c}\text { Liquidus } \\
\text { slope }\left(\boldsymbol{m}_{\mathbf{L}}\right)\end{array}$ & $\begin{array}{c}\text { Partition } \\
\text { coefficient } \\
(\boldsymbol{k})\end{array}$ & $\begin{array}{c}\text { Maximum } \\
\text { concentration } \\
\mathbf{( w t . \% )}\end{array}$ & GRF \\
\hline $\mathrm{Al}$ & -6 & 0.5 & 0.5 & 1 \\
$\mathrm{Ag}$ & -3 & 0.02 & 3.7 & 11 \\
$\mathrm{Bi}$ & -2 & 0.2 & 53 & 86 \\
$\mathrm{Co}$ & -7 & 0 & 0.02 & 0.1 \\
$\mathrm{Cu}$ & -7 & 0 & 0.9 & 6 \\
$\mathrm{In}$ & -2 & 0.3 & 4.0 & 6 \\
$\mathrm{Mn}$ & -9 & 0 & 0.02 & 0.2 \\
$\mathrm{Ni}$ & -6 & 0.04 & 0.04 & 0.2 \\
$\mathrm{Zn}$ & -4 & 0.05 & 7.8 & 29
\end{tabular}

A high value of $G R F$ is desired to most effectively promote constitutional undercooling. (Data calculated via ThermoCalc V.3 TCSLD3. ${ }^{[57]}$ ) fractions of small, dispersed IMC phases that can act as dislocation blockers within the solder matrix. The ideal Snbased solder microstructure will need to be optimized for these two properties. Given that current Sn-based solders often contain only one unique $\beta$-Sn nucleation site within a solder joint microstructure, a shift in grain refinement of $\beta$ $\mathrm{Sn}$ to include 4-5 unique $\beta$-Sn nucleation sites within a single solder joint may mitigate the reductions in fatigue life from decreased primary IMC presence by increased fatigue life via grain refinement. Future experimental research on solute additions and computational modeling of nucleant cluster formations within the Sn-alloy liquids should be performed to determine the viability of such approaches in Sn-based solders.

\section{High Temperature Interconnect Technologies}

Although the current RoHS exemption for high-Pb hightemperature solders is being reviewed by the European Commission with likely renewal through 2021, research in high-temperature $\mathrm{Pb}$-free alternatives has intensified. This is driven by both the need to find acceptable replacements for current uses of high- $\mathrm{Pb}$ solders and the demand for even higher temperature interconnect (HTI) technologies for electronic systems in increasingly harsh environments. The most widely used commercial $\mathrm{Pb}$-free solder for high temperature applications is the $\mathrm{Au}-20 \mathrm{Sn}$ wt.\% eutectic alloy $\left(T_{\mathrm{e}}=278{ }^{\circ} \mathrm{C}\right) .{ }^{[58-63]}$ However, due to the high price of $\mathrm{Au}$, $\mathrm{Au}-\mathrm{Sn}$ alloys have been used primarily in high reliability applications including step-soldering in RF packages, hermetic sealing, aerospace, military, and medical electronics.

At the same time that alternatives to high- $\mathrm{Pb}$, high temperature solders are being sought, the operating temperatures of integrated circuits are increasing and the environments in which they are being used are becoming more extreme. The trend to more compact auto engine compartments is placing control systems closer to the engines and actuators, and increasing exposure of vulnerable integrated circuitry to higher temperatures, vibration, and thus, conditions for fatigue and failure. Semiconductors based on $\mathrm{GaN}$, III-Vs, SiC, and diamond can operate at significantly higher temperatures than $\mathrm{Si}$, whose maximum operating temperature is approximately $200{ }^{\circ} \mathrm{C}$. This creates the need for new, RoHS-compliant bonding solutions for die-attach, insulatedgate bipolar transistor (IGBT) attach, and power electronics to replace high- $\mathrm{Pb}$ solders, $\mathrm{Pb}$-free solders, and thermal interface materials used today.

A wide range of non-solder alternatives have been researched over the last ten years resulting in a range of commercial products being currently offered. These technologies include sintering of $\mathrm{Ag}$ and $\mathrm{Cu}$ nanoparticles, coreshell nanoparticles, mixtures of coarser $\mathrm{Cu}$ with $\mathrm{Ag}$ nanoparticles, Ag-filled adhesives, Bi-Ag-X alloys, transient liquid phase sintering, and foil-based transient liquid phase bonding. ${ }^{[64-70]}$ For an HTI to be an acceptable substitute for high- $\mathrm{Pb}$ solders in a given application, the HTI must: 
1. Perform within an acceptable range of the electrical, thermal, and mechanical requirements for the application.

2. Form at temperatures less than or equal to commercial high- $\mathrm{Pb}$ solders it is replacing $\left(<300{ }^{\circ} \mathrm{C}\right)$.

3. Perform reliably for typical operation and use conditions, including during thermal cycling to low and high temperatures depending on the operating ranges, which can reach $400{ }^{\circ} \mathrm{C}$ for some applications.

4. Exhibit acceptable mechanical, thermal, and electrical performance after long-term aging and use.

Among the alternative strategies for forming HTIs, approaches using either a liquid or a solid transient phase to meet these criteria are being widely pursued with commercial products currently available based on several different compositions. In the case of a liquid transient phase, a low melting point liquid reacts with a higher melting point solid to solidify isothermally by interdiffusion and/or IMC formation. Two classic examples of isothermal solidification by Rahman et al. are (1) a Cu-Ni liquid in contact with pure $\mathrm{Ni}$ forms a $\mathrm{Cu}-\mathrm{Ni}$ solid solution by interdiffusion with no remaining liquid phase and (2) the reaction of liquid $\mathrm{Sn}$ with $\mathrm{Cu}$ forms two IMCs on solid $\mathrm{Cu}$, and if annealed long enough to reach equilibrium, forms a single IMC on $\mathrm{Cu}$. Both processes are based on isothermal solidification by interdiffusion; the key difference between the two is that the liquid is eliminated by the formation of an intermetallic phase in the $\mathrm{Cu}-\mathrm{Sn}$ example versus interdiffusion to form a $\mathrm{Ni}-\mathrm{Cu}$ solid solution in the $\mathrm{Cu}-\mathrm{Ni}$ example. ${ }^{[71]}$ It is interesting to note that similar approaches can be used with a transient solid phase to raise the melting temperature of the remaining phases in the solder interconnect. For example, Zhu et al. recently developed a transient solid reaction system by first heating a solid tri-layer interconnect, Ni/eutectic Au-20Sn wt.\%/Ni, to above the eutectic temperature $\left(278{ }^{\circ} \mathrm{C}\right)$, then cooling it to $240{ }^{\circ} \mathrm{C}$ to solidify the liquid to form $\mathrm{AuSn}$ and $\mathrm{Au}_{5} \mathrm{Sn}$ ( $\varsigma^{\prime}$ phase), and finally transforming it into a Ni- $\mathrm{Ni}_{3} \mathrm{Sn}_{4}-\mathrm{Au}_{5} \mathrm{Sn}_{-}-\mathrm{Ni}_{3} \mathrm{Sn}_{4}-\mathrm{Ni}$ multilayer structure by annealing the tri-layer for $100 \mathrm{~h}$ at $240{ }^{\circ} \mathrm{C}$. The resulting $\varsigma$ ' phase shows a region of significant solid solubility, with the IMC composition shifting to higher $\mathrm{Au}$ concentrations and higher temperature stability as $\mathrm{Ni}_{3} \mathrm{Sn}_{4}$ continues to form. ${ }^{[63]}$

Transient phase processes in Sn-based systems have been referred to by various names and acronyms by different research groups. The terms "transient liquid phase sintering" (TLPS), "liquid phase diffusion bonding" (LPDB), "transient liquid phase bonding" (TLPB), and solid-liquid interdiffusion (SLID) have all been used to describe bonding of two substrates via isothermal solidification reactions between a low melting temperature phase (LTP) and the high melting temperature (HTP) substrates. ${ }^{[63,67,69]}$ In this paper, the term LPDB will be used, although all can be used interchangeably. During processing when the temperature is heated higher than the solidus of the LTP, liquid forms and wets the HTP and the substrate surfaces. Typically the LTP is heated above its liquidus so that the LTP is completely molten. Isothermal solidification occurs by interdiffusion such that no liquid remains. The role of added HTP particles is to increase the surface area for interdiffusion and reaction, to reduce the time needed for sufficient reaction, rather than being limited by the surface area of the substrates. The underlying principle is the same with or without HTP particles added to the LTP. In this paper we focus on two approaches to HTI alloy and system design for LPDB systems for different applications. The first approach illustrates how metastability can be exploited in the $\mathrm{Cu}-\mathrm{Ni}-\mathrm{Sn}$ ternary to create a pseudo-binary LPDB system using a $\mathrm{Sn}-\mathrm{Cu}-\mathrm{Ni}$ LTP alloy and $\mathrm{Cu}-10 \mathrm{Ni}$ wt.\% binary solid solution HTP. The second approach presents a thermodynamic framework to bound alloy candidates for ternary and higher order LPDB systems as a function of processing and operating temperatures.

\subsection{Liquid Phase Diffusion Bonding in the Cu-Ni-Sn System}

Liquid phase diffusion bonding reactions in the $\mathrm{Sn}-\mathrm{Cu}-$ $\mathrm{Ni}$ system were examined by McCluskey, Greve, and Moeini with a Sn-3.5Ag LTP in combination with $\mathrm{Cu}, \mathrm{Ni}$, or mixture of $\mathrm{Cu}$ and $\mathrm{Ni}$ powders with $\mathrm{Ni}$ substrates as the HTP substrates. ${ }^{[67,68,72]}$ Samples were processed at a peak temperature of $300{ }^{\circ} \mathrm{C}$ in an inert atmosphere for approximately 30 minutes using $0.2 \mathrm{MPa}$ of applied pressure to reduce void formation. The resulting microstructures for $\mathrm{Ni}$ $\mathrm{Sn}$ and $(\mathrm{Cu}, \mathrm{Ni})-\mathrm{Sn}$ contained few voids; pockets of $\mathrm{Sn}$ in cross-sections of the bonds indicated incomplete solidification. Despite the presence of unreacted $\mathrm{Sn}$, shear tests of $\mathrm{Ag}$ metallized $\mathrm{Si}$ dies bonded to $\mathrm{Ni}$ substrates using this technique indicated that the bonds were able to withstand 10 $\mathrm{MPa}$ up to $435^{\circ} \mathrm{C}$ using mixed $\mathrm{Cu}$ and $\mathrm{Ni}$ particles as the HTP and up to $600{ }^{\circ} \mathrm{C}$ (test setup limit) with Ni HTP particles. ${ }^{[73]}$ These mechanical property results are consistent with the melting temperatures of the expected intermetallics in the systems: approximately $415{ }^{\circ} \mathrm{C}$ for $\mathrm{Cu}_{6} \mathrm{Sn}_{5}$ and $798{ }^{\circ} \mathrm{C}$ for $\mathrm{Ni}_{3} \mathrm{Sn}_{4}$. These results also demonstrate that the bonds may provide adequate performance at elevated temperatures even in the presence of isolated pockets of residual liquid.

The Cu-Ni-Sn ternary system has advantages over the binary $\mathrm{Sn}-\mathrm{Cu}$ system. Nickel, even in trace amounts, is soluble in $\mathrm{Cu}_{6} \mathrm{Sn}_{5}$ and suppresses the IMC's allotropic phase change upon cooling, i.e., stabilizing the high temperature hexagonal $\left(\mathrm{Cu}, \mathrm{Ni}_{6}\right)_{5} \mathrm{Sn}_{5}{ }^{[37]}$ However, as reported by McCluskey, when both $\mathrm{Cu}$ and Ni HTP particles are used, the system has competing reactions between the two binaries: with the formation of $\mathrm{Cu}_{3} \mathrm{Sn}$ and $\mathrm{Cu}_{6} \mathrm{Sn}_{5}$ between $\mathrm{Cu}$ and $\mathrm{Sn}$, and the formation of $\mathrm{Ni}_{3} \mathrm{Sn}_{4}$ between $\mathrm{Ni}$ and $\mathrm{Sn}$. If the $\mathrm{Cu}_{6} \mathrm{Sn}_{5}$ forms quickly enough such that little Ni from the liquid is available to be incorporated into the IMC, the low temperature, more brittle monoclinic $\mathrm{Cu}_{6} \mathrm{Sn}_{5}$ can form. Furthermore, as seen in reactions in BGAs in which one substrate is $\mathrm{Cu}$ and one is $\mathrm{Ni}$, the two intermetallics in contact with the liquid can change in both composition and phase over time since they are not in thermodynamic equilibrium.

Choquette and Anderson avoided these issues by creating LPDB systems with $\mathrm{Cu}-10 \mathrm{Ni}$ wt.\% HTP alloy powders and Sn-0.7Cu-0.05Ni LTP powder (Nihon Superior, SN100C), 
leading to the formation of $(\mathrm{Cu}, \mathrm{Ni})_{6} \mathrm{Sn}_{5}$ in the processed joints. The microstructures formed by this powder paste reflowed with $30 \mathrm{~s}$ above liquidus $\left(227^{\circ} \mathrm{C}\right)$ to a peak temperature of $250{ }^{\circ} \mathrm{C}$ can be seen in Fig. 5. Liquid-phase diffusion bonding occurred between the tin alloy (white) and the solid $\mathrm{Cu}-\mathrm{Ni}$ powder (dark gray), with reaction formation of the $(\mathrm{Cu}, \mathrm{Ni})_{6} \mathrm{Sn}_{5}$ phase (light gray). No formation of $(\mathrm{Cu}, \mathrm{Ni})_{3} \mathrm{Sn}$ was observed. The absence of $(\mathrm{Cu}$,

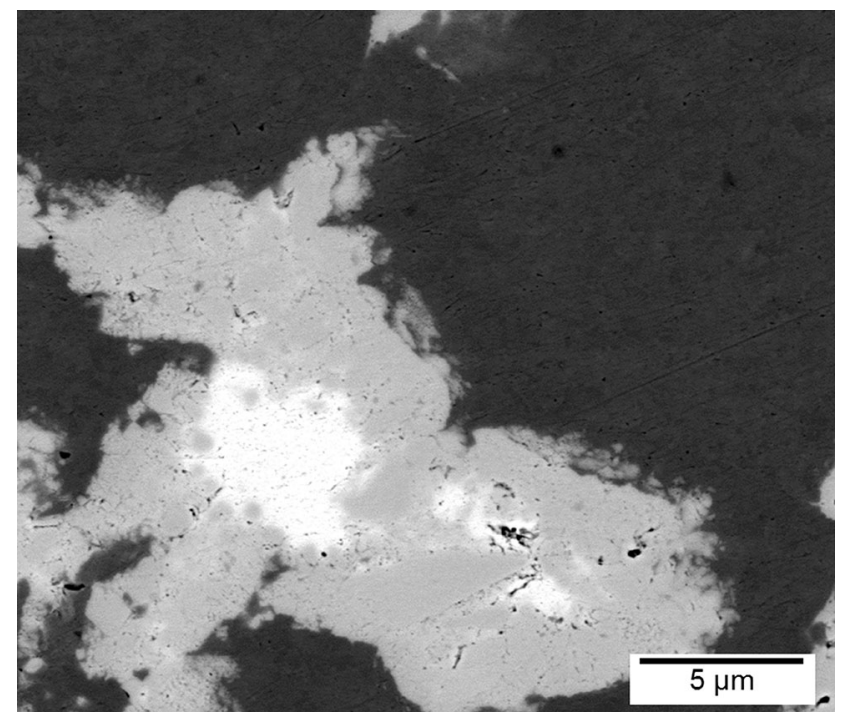

Fig. 5 LPDB microstructure of SN100C LTP and Cu-10 wt.\% $\mathrm{Ni}$ HTP particles (dark grey). $(\mathrm{Cu}, \mathrm{Ni})_{6} \mathrm{Sn}_{5}$ intermetallic compound (light grey), and residual Sn (white) (Previously unpublished micrograph provided by the author)

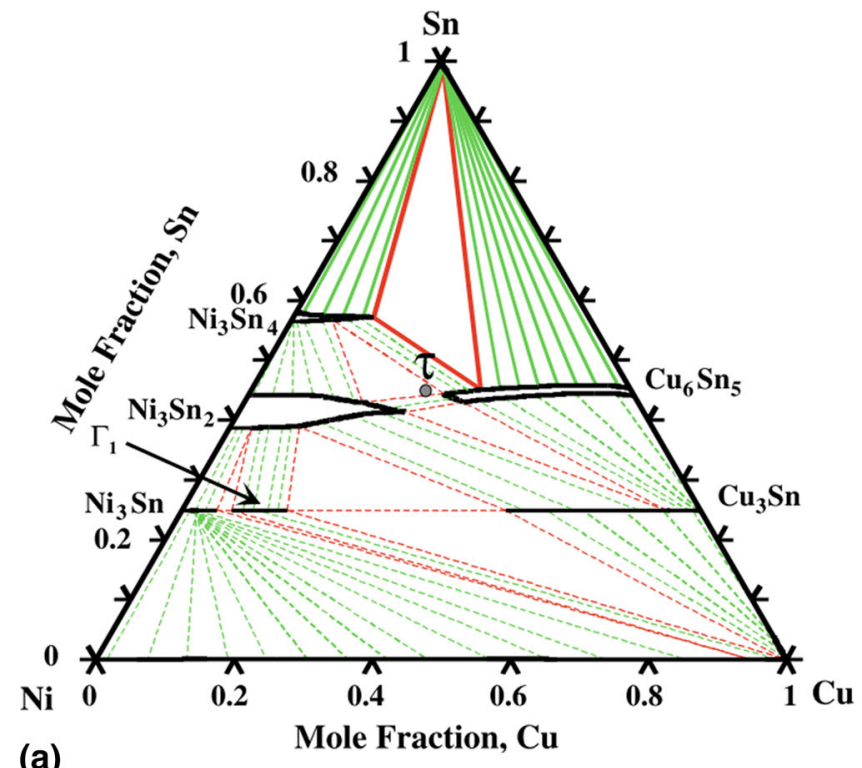

(a)

Mole Fraction, $\mathrm{Cu}$

Fig. 6 (a) Calculated metastable equilibria in the $\mathrm{Sn}-\mathrm{Cu}-\mathrm{Ni}$ systems at $240{ }^{\circ} \mathrm{C}$. The possible $\tau$-phase is indicated and dotted lines in the $\mathrm{Cu}-\mathrm{Ni}$ side of the diagram beyond the formation of $(\mathrm{Cu}, \mathrm{Ni})_{6} \mathrm{Sn}_{5}$ and $(\mathrm{Ni}, \mathrm{Cu})_{3} \mathrm{Sn}_{4}$ reflect the uncertainties in the phase equilibria. Plot reproduced from Ref 74. (b) Schematic reaction diagram represents the phases observed in diffusion couples composed of Cu-Ni $\mathrm{HTP}$ and $\mathrm{Sn}$ at around $240{ }^{\circ} \mathrm{C}$. The gold circles indicate the final phases remaining after complete consumption of the $\mathrm{Sn}$ for a $\mathrm{Cu}-10 \mathrm{wt} . \% \mathrm{Ni}$ HTP alloy (Color figure available online)
$\mathrm{Ni})_{3} \mathrm{Sn}$ has been reported previously for similar diffusion couples annealed at $240{ }^{\circ} \mathrm{C}$ by Vuorinen et al. and at $200{ }^{\circ} \mathrm{C}$ by Baheti et al. ${ }^{[74,75]}$ Baheti et al. presented evidence that $(\mathrm{Cu}, \mathrm{Ni})_{3} \mathrm{Sn}$ is not thermodynamically stable at $200{ }^{\circ} \mathrm{C}$ for $\mathrm{Ni}$ concentrations equal to or greater than $7.5 \mathrm{wt} \% \mathrm{Ni}$, and suggested that the absence of the thermodynamically stable ternary intermetallic was due to difficulty in nucleation of the phase. ${ }^{[75]}$ However, at $240{ }^{\circ} \mathrm{C}$, Vuorinen et al. argued that the absence of the $(\mathrm{Cu}, \mathrm{Ni})_{3} \mathrm{Sn}$ was kinetic in origin, i.e., that $(\mathrm{Cu}, \mathrm{Ni})_{3} \mathrm{Sn}$ was thermodynamically stable, but did not form due to rapid growth of $(\mathrm{Cu}, \mathrm{Ni})_{6} \mathrm{Sn}_{5} .{ }^{[74]}$ This latter interpretation is supported by phase equilibrium experiments by $\mathrm{Lin}$ et al. that showed $(\mathrm{Cu}, \mathrm{Ni})_{3} \mathrm{Sn}$ in equilibrium with $\mathrm{Cu}-\mathrm{Ni}$ alloys at $240{ }^{\circ} \mathrm{C}$. ${ }^{[76]}$ The most important feature of this system is, therefore, that it can be treated as two pseudo-binaries. This can be understood by comparing the $240{ }^{\circ} \mathrm{C}$ isothermal section of the phase diagram (Fig. 6a) with what we refer to as a "reaction diagram" (Fig. 6b). This isothermal reaction diagram schematically shows the phases observed during the short annealing times required for LPDB systems. Many binary and ternary phases present in the equilibrium phase diagram are missing in the diffusion couples as discussed above. The $\mathrm{Cu}-\mathrm{Ni} \mathrm{HTP}$ alloys in contact with $\mathrm{Sn}$ form either $(\mathrm{Cu}$, $\mathrm{Ni})_{6} \mathrm{Sn}_{5}$ or $(\mathrm{Ni}, \mathrm{Cu})_{3} \mathrm{Sn}_{4}$ depending on the HTP alloy composition, and at low $\mathrm{Ni}$ concentrations $(\mathrm{Cu}, \mathrm{Ni})_{3} \mathrm{Sn}$ is also observed. This diagram helps to visualize the resulting LTP composition regimes.

Recent experiments testing several volume ratios of LTP:HTP (Sn alloy powder:Cu-10Ni wt.\% powder) showed formation of large voids and flux trapping at a ratio of 25 phases forming from diffusion couples in various HTP and

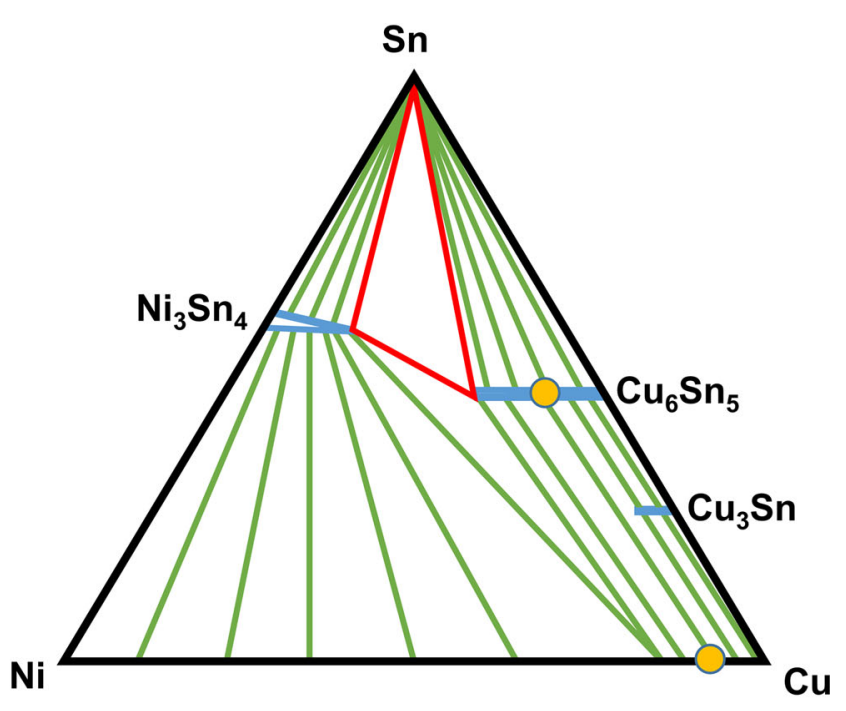

(b) 


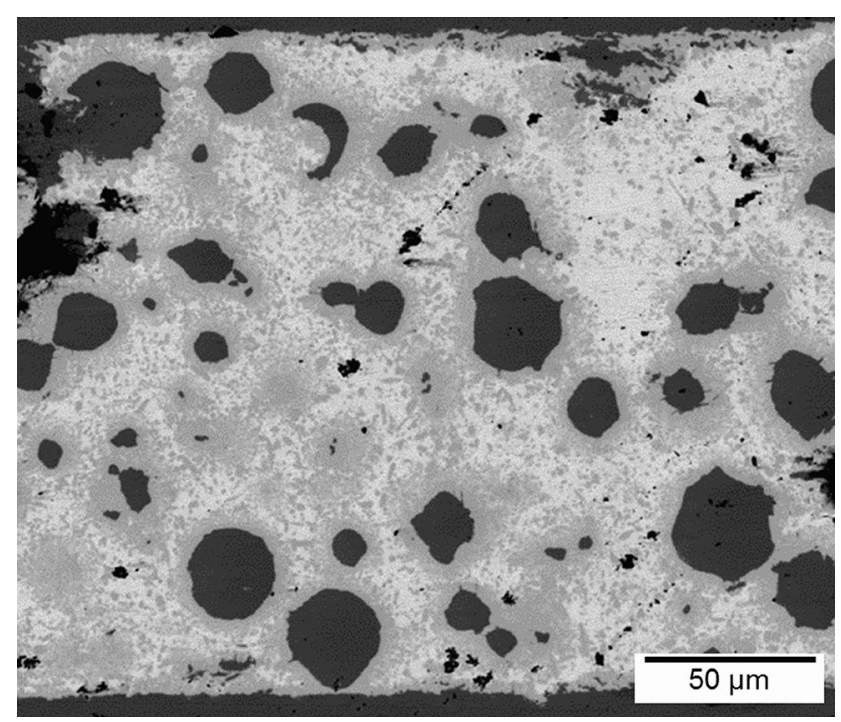

Fig. 7 LPDB microstructure of 25 vol. \% Cu-10 wt.\% Ni HTP particles (black) and 75 vol.\% SN100C LTP after reflow processing for 30 s above the liquidus $\left(227^{\circ} \mathrm{C}\right)$ with a peak temperature of $250{ }^{\circ} \mathrm{C}$ (Previously unpublished micrograph provided by the author)

vol.\%:75 vol.\% (LTP:HTP). This issue was resolved when the ratio of LTP:HTP was increased to 75 vol. $\%: 25$ vol. $\%$ (LTP:HTP). This increased fraction of liquid phase allowed for better wetting, greater pore filling, significant rearrangement within the LTP/HTP mixture before IMC formation, and the flux to be expelled, thus reducing porosity. A typical microstructure resulting from the 75 vol. \% LTP:25 vol.\% HTP ratio is shown in Fig. 7 , after 30 s reflow above liquidus $\left(227{ }^{\circ} \mathrm{C}\right)$ with a peak reflow temperature of $250{ }^{\circ} \mathrm{C}$. Approximately $10 \mu \mathrm{m}$ of $(\mathrm{Cu}, \mathrm{Ni})_{6} \mathrm{Sn}_{5}$ was observed to have formed and significant residual Sn-liquid was left surrounding the HTP particles. For a viable LPDB system, there must be significant "bridge" formation (IMC growth) between the $(\mathrm{Cu}, \mathrm{Ni})_{6} \mathrm{Sn}_{5}$ coated HTP particles and percolation of the IMC to form a rigid structure. In Fig. 7 there is little evidence that this has occurred. As noted above, the results of Greve et al. indicated that complete consumption of the $\mathrm{Sn}$ is not required, however, the acceptable levels of residual liquid as a function of starting microstructure are not known. ${ }^{[73]}$ There are at least two minimum conditions for bridge formation. First, there must be enough HTP alloy to consume all the $\mathrm{Sn}$; for the formation of $\mathrm{Cu}_{6} \mathrm{Sn}_{5}$ between $\mathrm{Cu}$ and $\mathrm{Sn}$, the critical ratio is 35 vol.\%:65 vol.\% (Cu:Sn). Therefore, the amount of HTP will need to be increased for the reaction to continue. The second is that the $(\mathrm{Cu}$, $\mathrm{Ni})_{6} \mathrm{Sn}_{5}$-coated HTP particles must be touching such that the residual liquid is isolated at the HTP particle junctions. Whether this will occur during processing for a given ratio of LTP:HTP will depend on a number of factors, including the reaction rate and the starting HTP particle size. It is interesting to note that Vuorinen et al. reported that the growth rate of $(\mathrm{Cu}, \mathrm{Ni})_{6} \mathrm{Sn}_{5}$ at $240{ }^{\circ} \mathrm{C}$ increased as a function of $\mathrm{Ni}$ in the $\mathrm{Cu}-\mathrm{Ni}$ alloy, reaching a maximum at approximately 10 at.\% Ni. ${ }^{[74]}$ In their experiments with $\mathrm{Cu}$ -
10 at. $\% \mathrm{Ni}$ in contact with $\mathrm{Sn}$, the $(\mathrm{Cu}, \mathrm{Ni})_{6} \mathrm{Sn}_{5}$ thickness was approximately $10 \mu \mathrm{m}$ after $10 \mathrm{~min}$ at $240{ }^{\circ} \mathrm{C}$, in contrast to the $10 \mu \mathrm{m}$ after $30 \mathrm{~s}$ at $250{ }^{\circ} \mathrm{C}$ seen here by Choquette and Anderson. ${ }^{[69]}$ Optimization of the $\mathrm{Cu}-\mathrm{Ni}-\mathrm{Sn}$ LPDB system will require quantifying the effects of LTP:HTP ratio, HTP particle size, packing, and processing temperature on liquid consumption rate, the location of the residual liquid, and the resulting mechanical properties of the LPDB structure. Practical processing and compatibility considerations will dictate the maximum acceptable processing temperatures and times, and therefore, under what conditions the $\mathrm{Cu}-\mathrm{Ni}-\mathrm{Sn} \mathrm{LPDB}$ system can be used.

\subsection{Thermodynamic Framework for Identifying New Ternary LPDB Systems}

The relationship between the equilibrium phases in Snbased ternary phase diagrams and the specific interdiffusion paths for soldering and bond formation have been studied extensively for a range of systems. For example, Chen et al., determined both the phase diagrams and the diffusion paths for a range of Sn-In alloys reacting with Ag. ${ }^{[77]}$ These studies and the relationships they have revealed can be leveraged to identify new LPDB formulations and processing paths for multi-component systems. In particular, we suggest that design criteria can be defined and used as a screening tool to identify potential LTP and HTP compositions based on examination of ternary phase diagrams, either calculated or experimental. These criteria described below are based on (1) melting temperature of the LTP, (2) formation of IMCs that consume components of the liquid phase, (3) three phase equilibrium between the terminal liquid, the IMC, and any third phase that must precipitate for the liquid fraction to decrease, and (4) the temperature at which reactions occur in the solidified structure as it is heated.

The binary $\mathrm{Cu}-\mathrm{Sn}$ LPDB system provides a simple starting point before proceeding to discuss three-component systems. The binary $\mathrm{Cu}-\mathrm{Sn}$ phase diagram shown in Fig. 8 illustrates several of the key thermodynamic characteristics necessary for LPDB. The first characteristic is that processing must occur above the melting point of the LTP, which in the case of pure $\mathrm{Sn}$ is $232{ }^{\circ} \mathrm{C}$. The second characteristic is that the resulting intermetallic phases from a given HTPLTP combination incorporate $\mathrm{Sn}$, the primary component in the liquid. Consider the interface between a small volume of liquid $\mathrm{Sn}$ in contact with a relatively large volume of solid $\mathrm{Cu}$ at $250{ }^{\circ} \mathrm{C}$. The blue, double-arrow line in Fig. 8 identifies the $250{ }^{\circ} \mathrm{C}$ isotherm on the $\mathrm{Cu}-\mathrm{Sn}$ phase diagram. Initially, $\mathrm{Cu}$ dissolves into the liquid $\mathrm{Sn}$. (It is assumed that the liquid is well mixed.) Once the $\mathrm{Sn}$ becomes saturated with $\mathrm{Cu}, \mathrm{Cu}_{6} \mathrm{Sn}_{5}$ nucleates. The $\mathrm{Cu}_{6} \mathrm{Sn}_{5}$ typically develops a scalloped interface, and $\mathrm{C}_{3} \mathrm{Sn}$ layer forms between the $\mathrm{Cu}$ and $\mathrm{Cu}_{6} \mathrm{Sn}_{5}$. There are now 3 interfaces: $\mathrm{Cu}-\mathrm{Cu}_{3} \mathrm{Sn}, \mathrm{Cu}_{3} \mathrm{Sn}$ $\mathrm{Cu}_{6} \mathrm{Sn}_{5}$, and $\mathrm{Cu}_{6} \mathrm{Sn}_{5}-\mathrm{Sn}$. The evolution of phases at the $\mathrm{Cu}-$ $\mathrm{Sn}$ interface follows the line across the isotherm, indicated in Fig. 8.

Ternary elements may be added to the LTP for several purposes. An alloying component may be used to modify the IMC phases in equilibrium with the liquid LTP. 


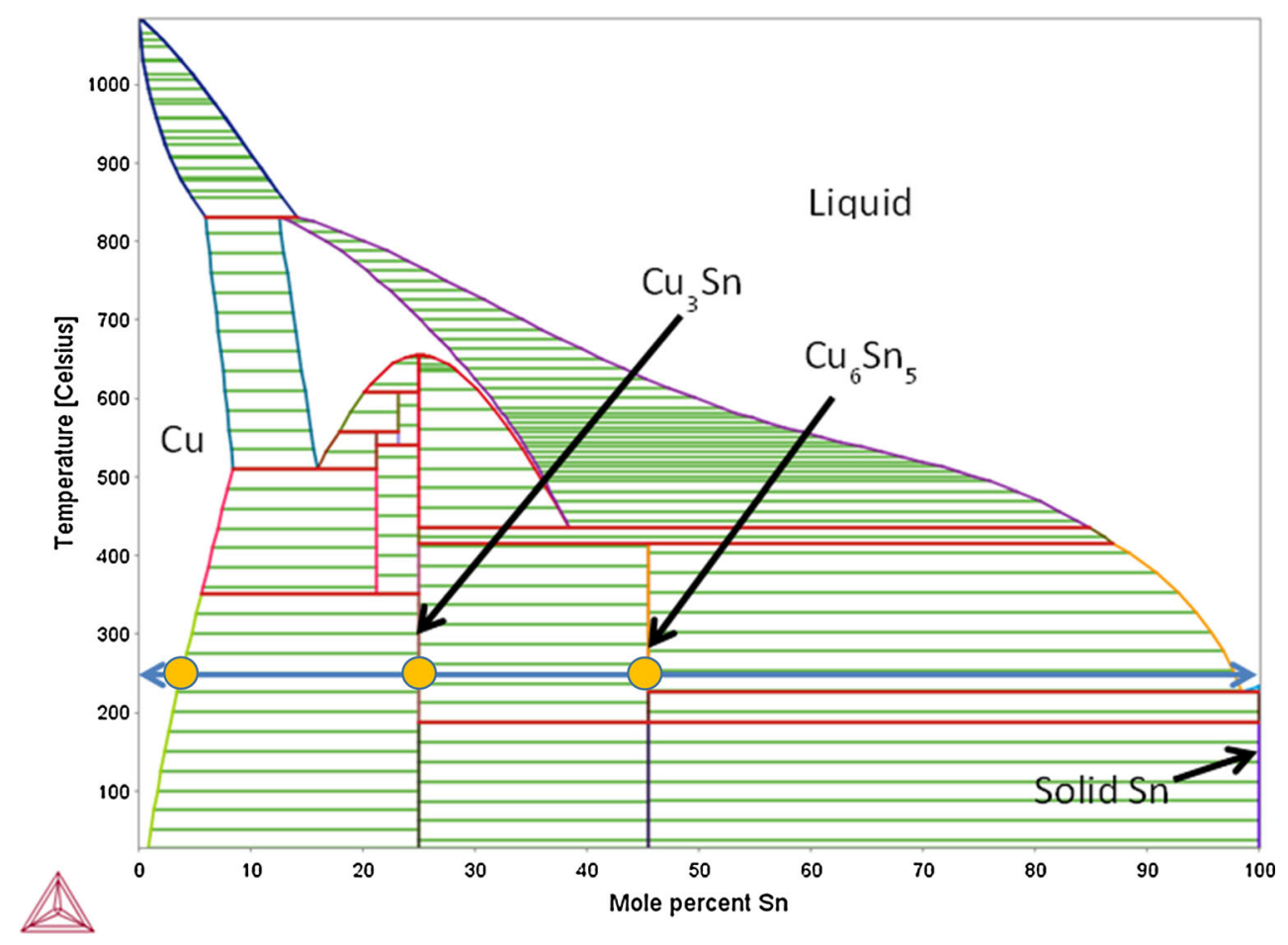

Fig. $8 \mathrm{Cu}$-Sn phase diagram generated using ThermoCalc with database TCSLD1. ${ }^{[57]}$ The gold circles indicate the phases observed when the liquid phase is consumed in typical $\mathrm{Cu}-\mathrm{Sn}$ LPDB reactions. Further annealing may lead to the disappearance of at least one of the two phases depending on the interdiffusion kinetics (Color figure available online)

Alternative IMC phases may be favored based on mechanical properties or melting temperature. A three-component system also results in the regions of three-phase equilibrium. Solute rich alloys can be therefore leveraged to reduce processing time by precipitation of a new phase in the liquid as the IMC forms, i.e., solidification occurs both by IMC formation and precipitation. The precipitation of a new phase is not itself diffusion limited, but it is determined by the rate of IMC formation. A liquid composition in threephase equilibrium with the dominant IMC phase and the precipitate phase is necessary to gain this benefit of two concurrent forms of isothermal solidification. The third characteristic is that the terminal liquid must be in equilibrium with both the IMC and the third precipitating phase in order for the liquid to be consumed. The fourth characteristic is determined by the use temperature: the precipitating phase must have a melting point higher than the intended use temperature, and the precipitating phase must not react to form a liquid at the intended use temperature.

In the discussion that follows, these four thermodynamic characteristics are discussed for three Sn-Bi ternaries: Ag$\mathrm{Bi}-\mathrm{Sn}, \mathrm{Cu}-\mathrm{Bi}-\mathrm{Sn}$, and Ni-Bi-Sn, and three Sn-In ternaries: Ag-In-Sn, Cu-In-Sn, and Ni-In-Sn. Phase diagrams were calculated using Thermo-Calc (version 3) with the solder solution database version $1 .{ }^{[57]}$ Isothermal sections at $1{ }^{\circ} \mathrm{C}$ intervals were generated and compared with experimental results from the literature, such as Ref 78 .

\subsection{Potential LPDB Systems}

3.3.1 Sn-Ag, Sn-Cu, or Sn-Ni. Typical substrate and HTP powder compositions are composed of $\mathrm{Ag}, \mathrm{Cu}$, or $\mathrm{Ni}$, and form the basis of the starting binaries. The elements $\mathrm{Ag}$ and $\mathrm{Cu}$ form eutectics with $\mathrm{Sn}$ at 220 and $227^{\circ} \mathrm{C}$, respectively. Nickel does not significantly decrease the melting temperature of $\mathrm{Sn}$, and therefore does not affect the LTP melting temperature, but it may be used to modify the initial equilibrium phase with $\mathrm{Cu}$, as in the $\mathrm{Cu}-\mathrm{Ni}-\mathrm{Sn}$ system. Because all three HTPs form IMC phases with Sn, effective solute compositions are limited to the liquidus composition in equilibrium with the IMC at the isothermal solidification temperature. Hyper-eutectic LTP compositions will result in primary IMC in the liquid that remains solid during processing, and may be of benefit to reduce the amount of IMC formation necessary to isothermally solidify and form interconnects.

3.3.2 Bi-Sn LTP with Ag, Cu, or Ni. The Sn-Bi eutectic reaction occurs near $138^{\circ} \mathrm{C}$ and 57 wt.\% Bi (43 at.\% Bi). The element $\mathrm{Bi}$ forms simple binary eutectics with $\mathrm{Ag}$ $\left(T_{\mathrm{e}}=262.5{ }^{\circ} \mathrm{C}\right)$ and $\mathrm{Cu}\left(T_{\mathrm{e}}=270.6{ }^{\circ} \mathrm{C}\right)$, with no IMCs. The Ni-Bi phase diagram contains two IMCs, NiBi and $\mathrm{NiBi}_{3}$, and has a eutectic reaction $\left(T_{\mathrm{e}}=271{ }^{\circ} \mathrm{C}\right)$, however, the $\mathrm{NiBi}_{3}$ IMC has been observed only in long-term annealing experiments after reaction between $\mathrm{Ni}$ and $\mathrm{Sn}$ $\mathrm{Bi}$ alloys with $\mathrm{Bi}$ content in the alloy $>96.5$ at.\% $\mathrm{Bi}{ }^{[79]}$ Given the deep $\mathrm{Sn}-\mathrm{Bi}$ eutectic, the maximum effective addition of $\mathrm{Bi}$ is limited only by the compositions that are 
liquid at the targeted processing temperature. In fact, the amount of $\mathrm{Bi}$ solute may be leveraged to minimize the amount of $\mathrm{Sn}$ that must be consumed by IMC formation for isothermal solidification. The ternary Ag-Bi-Sn (Ag HTP substrate) will form a single IMC $\mathrm{Ag}_{3} \mathrm{Sn}$, with the rejected $\mathrm{Bi}$ phase precipitating from the terminal liquid as the IMC grows. The isothermal sections from the phase diagram and the corresponding reaction diagrams contain the same phases, with the exception of the $\varsigma-A g$ phase. The ternary $\mathrm{Ni}-\mathrm{Sn}-\mathrm{Bi}$ is also compatible with LPDB, since $\mathrm{Ni}_{3} \mathrm{Sn}_{4}$ is the only IMC that forms in diffusion couples with $\mathrm{Sn}-\mathrm{Bi}$ alloys, and it is in equilibrium with the rejected $\mathrm{Bi}$ phase. For Bi$\mathrm{Ni}-\mathrm{Sn}$, the isothermal sections of the phase diagram and the corresponding reaction diagrams are similar, with the exception of the Ni-Bi IMCs.

The ternary $\mathrm{Cu}-\mathrm{Sn}-\mathrm{Bi}$ is both simpler, and yet, more complicated than the Ag-Bi-Sn and $\mathrm{Bi}-\mathrm{Ni}-\mathrm{Sn}$ systems, primarily due to the two equilibrium $\mathrm{Cu}-\mathrm{Sn}$ IMCs $\left(\mathrm{Cu}_{6} \mathrm{Sn}_{5}\right.$ and $\mathrm{Cu}_{3} \mathrm{Sn}$ ) that also form in the diffusion couples. Since Bi does not react with $\mathrm{Cu}$, it must precipitate as a solid in order for isothermal solidification to proceed. Both $\mathrm{Cu}-\mathrm{Sn} \mathrm{IMC}$ phases are in equilibrium with Bi below $200{ }^{\circ} \mathrm{C}$, but only $\mathrm{Cu}_{3} \mathrm{Sn}$ is in equilibrium with $\mathrm{Bi}$ above $200{ }^{\circ} \mathrm{C}$. The $\mathrm{Cu}-\mathrm{Sn}-$ $\mathrm{Bi}$ ternary system exhibits the following Class II reaction at approximately $200{ }^{\circ} \mathrm{C}: \quad \mathrm{Cu}_{3} \mathrm{Sn}+\mathrm{L} \rightarrow \mathrm{Cu}_{6} \mathrm{Sn}_{5}+\mathrm{Bi}^{[80]}$ Isothermal sections above and below $200{ }^{\circ} \mathrm{C}$ are shown in Fig. 9. Since all the equilibrium phases are observed in diffusion couples, isothermal sections can be used as reaction diagrams. At $170{ }^{\circ} \mathrm{C}$, reactions for all $\mathrm{Sn}$-Bi LTP alloy compositions to the left of the terminal liquid composition in contact with $\mathrm{Cu}$ lead to the formation of
$\mathrm{Cu}_{6} \mathrm{Sn}_{5}$ in contact with the liquid. As the IMC grows, the liquid composition shifts until it reaches the terminal liquid composition (blue star, Fig. 9a) for the three-phase equilibrium triangle for $\mathrm{Cu}_{6} \mathrm{Sn}_{5}$ and solid $\mathrm{Bi}$. As the IMC continues to grow, the amount of liquid also decreases by precipitation of the $\mathrm{Bi}$, until all liquid is consumed. Additionally, there is then also the formation of the $\mathrm{Cu}_{3} \mathrm{Sn}$ phase between $\mathrm{Cu}$ and $\mathrm{Cu}_{6} \mathrm{Sn}_{5}$. The final phases in the LPDB structure are those indicated by the gold circles (Fig. 9a). In contrast, at temperatures above $200{ }^{\circ} \mathrm{C}\left(260{ }^{\circ} \mathrm{C}\right.$ isothermal shown in Fig. 9b), Sn-rich $\mathrm{Sn-Bi}$ liquids reach a terminal liquid composition (blue star, Fig. 9b) in equilibrium with $\mathrm{Cu}_{6} \mathrm{Sn}_{5}$ and $\mathrm{Cu}_{3} \mathrm{Sn}$, not with solid Bi. Therefore, for Sn-rich $\mathrm{Sn}-\mathrm{Bi}$ alloys, the growth of $\mathrm{Cu}_{6} \mathrm{Sn}_{5}$ stops at this terminal liquid composition, and, hence, isothermal solidification proceeds until the $\mathrm{Cu}_{6} \mathrm{Sn}_{5}$ is completely consumed by growth of $\mathrm{Cu}_{3} \mathrm{Sn}$ (gold circles indicate final phases, Fig. 9b). Isothermal solidification is possible as low as the eutectic temperature for $\mathrm{Sn}$-rich $\mathrm{Sn}$-Bi alloys, but reaction of $\mathrm{Cu}_{6} \mathrm{Sn}_{5}$ and rejected $\mathrm{Bi}$ to form liquid limits processing and operating temperatures to below $200{ }^{\circ} \mathrm{C}$. In comparison, for Bi-rich $\mathrm{Sn}-\mathrm{Bi}$ alloy compositions above $200{ }^{\circ} \mathrm{C}, \mathrm{Cu}_{3} \mathrm{Sn}$ formation occurs in equilibrium with the Bi-rich liquid, shifting to higher $\mathrm{Bi}$ concentrations as $\mathrm{Cu}_{3} \mathrm{Sn}$ growth proceeds. With the terminal liquid composition indicated (black star, Fig. 9b), the reaction can go to completion avoiding the limitations posed by the equilibrium inversion at Sn-rich concentrations, with the final phases in the LPDB structure indicated by the black circles (Fig. 9b) The limiting factor for any of these ternaries with $\mathrm{Sn}-\mathrm{Bi}$ is the melting temperature of $\mathrm{Bi}, 271{ }^{\circ} \mathrm{C}$. The ternary $\mathrm{Sn}-\mathrm{Bi}$ LTPs

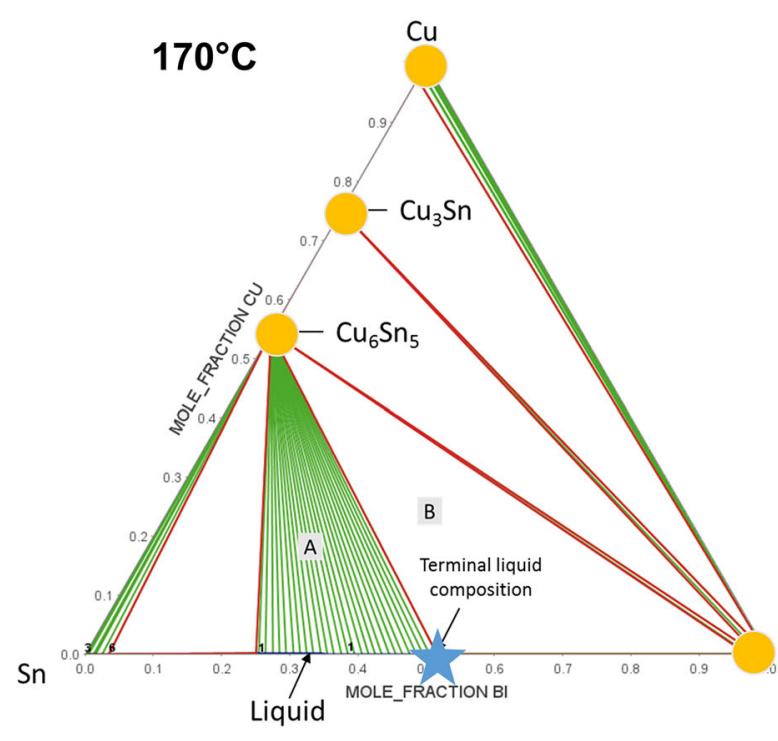

(a)

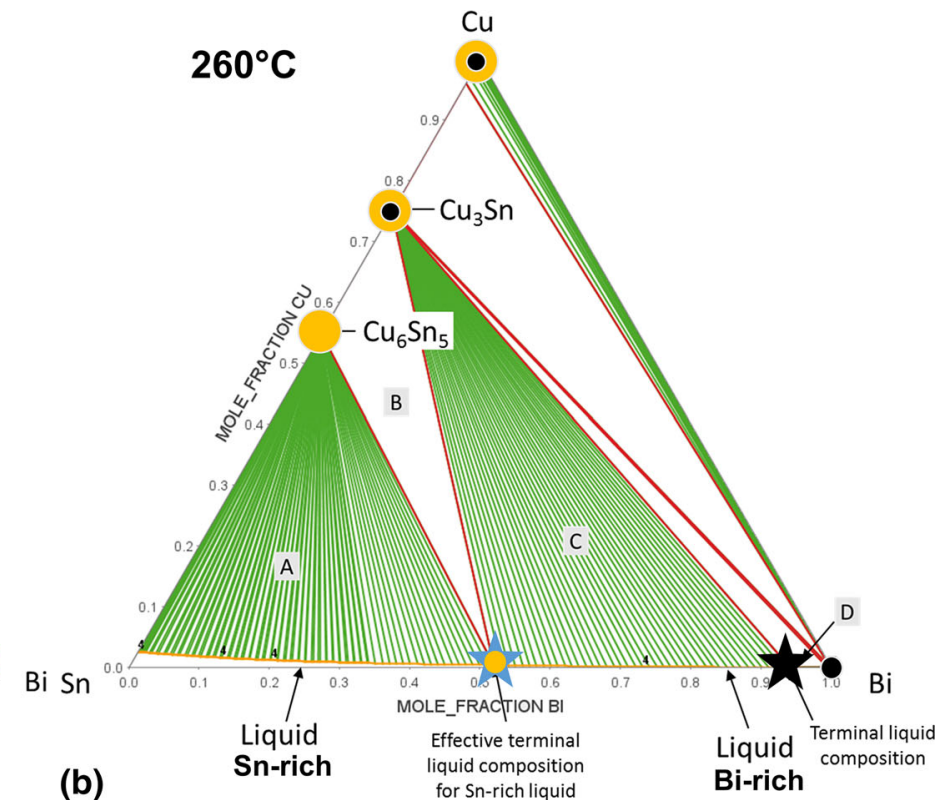

(b)

Fig. 9 Isothermal sections of the $\mathrm{Cu}-\mathrm{Sn}$-Bi phase diagram generated using Thermo-Calc V.3 with database TCSLD1. ${ }^{[57]}$ (a) At $170{ }^{\circ} \mathrm{C}$ all initial LTP liquid compositions can be isothermally solidified with the terminal liquid composition (blue star) as marked. The gold circles indicate the phases observed when the liquid phase is consumed in typical LPDB reactions. (b) At $260{ }^{\circ} \mathrm{C}$, Sn-rich LTP compositions end up at the terminal liquid composition (blue star) which leads to a stable liquid as long as $\mathrm{Cu}_{6} \mathrm{Sn}_{5}$ is in contact with the liquid. During reaction, Bi-rich LTP compositions shift to the terminal liquid composition (black star) and further reaction leads to the phases indicated by the black circles (Color figure available online) 
with $\mathrm{Ag}, \mathrm{Cu}$, or $\mathrm{Ni}$ are thus recommended for further investigation.

3.3.3 In-Sn LTP with Ag, $\mathrm{Cu}$, or Ni. In the binary, $\mathrm{Sn}$ and In react to form binary IMCs with extensive solid solubility; the Sn-In binary eutectic reaction is between two intermetallics and occurs near $120{ }^{\circ} \mathrm{C}$ and 50.9 wt.\% In (51.7 at.\% In). Both In and $\mathrm{Sn}$ form IMCs with $\mathrm{Ag}, \mathrm{Cu}$, and Ni. There have been a few observations of ternary compounds, but there are regions of complete solid solubility across the ternaries and more limited solubility of the third element in some binary IMCs. The ternary AgSn-In is minimally compatible with LPDB, because In-Sn alloys react with Ag to form Ag-In IMCs with limited solid solubility of Sn. With low temperature processing, this can lead to the precipitation of a Sn-In IMC that melts at $222{ }^{\circ} \mathrm{C}$, and therefore, does not offer any advantages over conventional $\mathrm{Pb}$-free solder alloys. In contrast, the ternary $\mathrm{Cu}-\mathrm{Sn}$-In is a promising LPDB system because the $\mathrm{Cu}_{6}(\mathrm{Sn}$, In) 5 phase in equilibrium with near-eutectic liquid compositions incorporates both components of the LTP, as seen in the calculated $\mathrm{Cn}$-Sn-In isothermal section of the ternary phase diagram in Fig.10, and has been shown to solidify isothermally by Sasangka et al. ${ }^{[81]}$ The ternary Ni-Sn-In exhibits similar characteristics to $\mathrm{Cu}-\mathrm{Sn}-\mathrm{In}$, but the solubil- ity of In in $\mathrm{Ni}_{3} \mathrm{Sn}_{4}$ is more limited. As with the Ag-In-Sn system, alloys of In-rich $\mathrm{Ni}-\mathrm{Sn}$-In are likely to form undesirable low-melting temperature In-Sn IMCs rather than $\mathrm{Ni}_{3}(\mathrm{Sn}, \mathrm{In})_{4}$. The ternaries of In-Sn LTPs with $\mathrm{Cu}$ and $\mathrm{Ni}$ exhibit promising characteristics over specific composition and temperature ranges and are, therefore, recommended for further investigation, particularly the $\mathrm{Cu}-\mathrm{In}-\mathrm{Sn}$ system.

3.3.4 Calculated Phase Diagrams and the Role of Kinetics. As demonstrated above, thermodynamic criteria for LPDB can be used to identify composition and temperature ranges that exist in promising ternary systems and warrant further study. The calculated isothermal sections and solidification paths can then be used as a starting point for understanding IMC formation and microstructural evolution. However, thermodynamics is only one aspect of selecting a formulation. The kinetics of IMC phase formation may change for a number of reasons with the addition of ternary components. As noted above, Baheti et al. found that increasing the $\mathrm{Ni}$ concentration in $\mathrm{Cu}-\mathrm{Ni}$ alloys ( $\leq 5$ at.\% Ni) decreased the growth rate of $(\mathrm{Cu}$, $\mathrm{Ni})_{3} \mathrm{Sn}$ until at $\mathrm{Cu}-5$ at. $\% \mathrm{Ni},(\mathrm{Cu}, \mathrm{Ni})_{3} \mathrm{Sn}$ was not present even though it was thermodynamically stable. This was attributed to the increase in the growth rate of $(\mathrm{Cu}, \mathrm{Ni})_{6} \mathrm{Sn}_{5}$

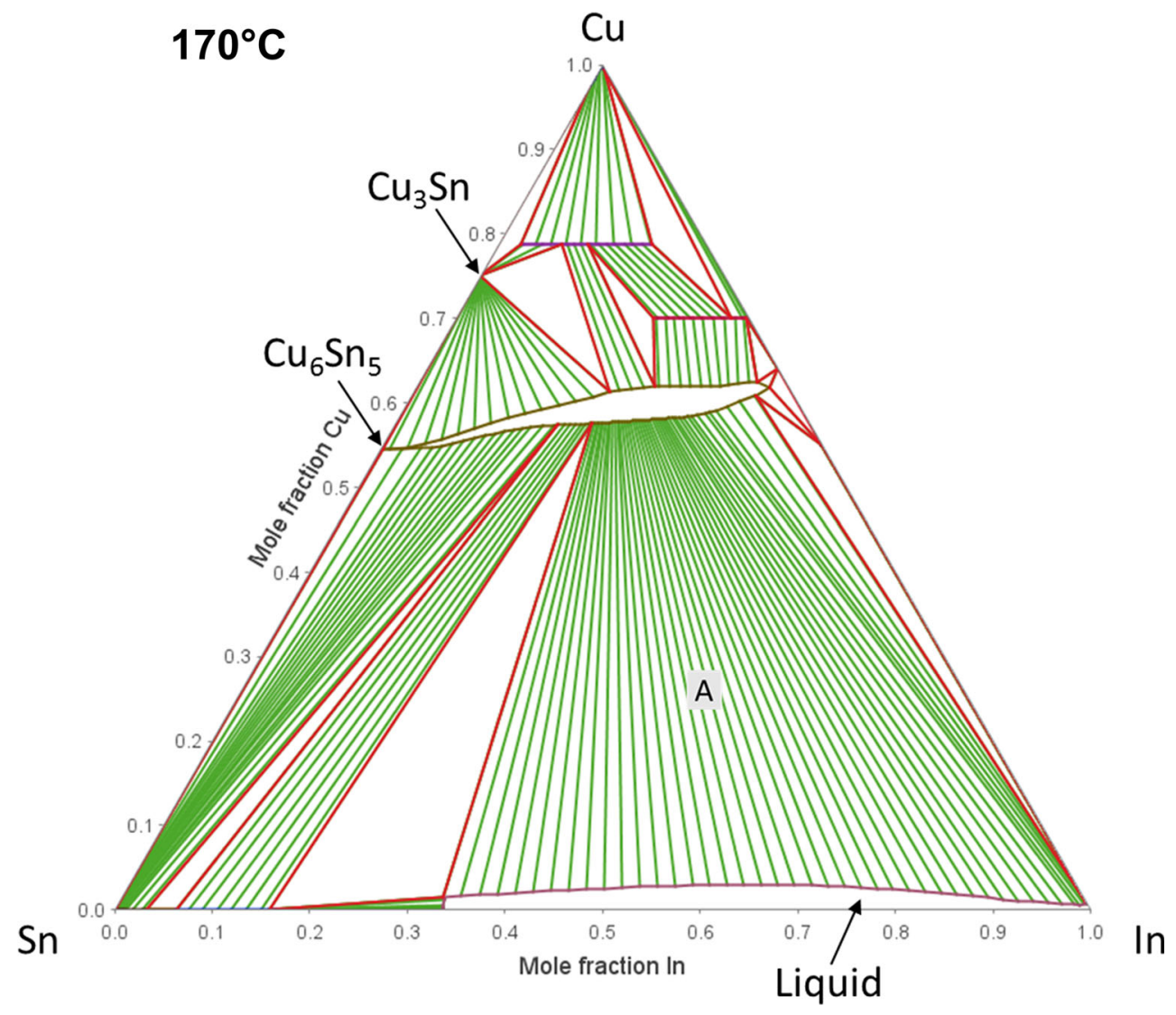

Fig. 10 Isothermal section of the $\mathrm{Cu}-\mathrm{Sn}$-In phase diagram at $170{ }^{\circ} \mathrm{C}$ generated using Thermo-Calc V.3 with database TCSLD1. ${ }^{[57]}$ All initial LTP liquid compositions can possibly be isothermally solidified forming a $\mathrm{Cu}_{6}(\mathrm{Sn} \text {, In })_{5}$ ternary solid solution. Experimental measurements of the specific reaction paths for different LTP compositions and the relative diffusivities of Sn and In in the IMCs still must be evaluated to determine what ranges can be used (Color figure available online) 
with increasing Ni concentrations, due to both the change in the relative diffusivities of $\mathrm{Sn}$ and $\mathrm{Cu}$ in the $(\mathrm{Cu}, \mathrm{Ni})_{6} \mathrm{Sn}_{5}$ phase and the increasing contribution of grain boundary diffusion to growth as the $(\mathrm{Cu}, \mathrm{Ni})_{6} \mathrm{Sn}_{5}$ grain size decreased with increasing $\mathrm{Ni}$ concentration. ${ }^{[75]}$ Stable phases at operating temperatures must be considered as well. For instance, Chen et al. found that $\mathrm{Sn}-20 \mathrm{In}$ wt.\% reacts with $\mathrm{Ag}$ to form a ternary IMC phase over a wide range of compositions at $250{ }^{\circ} \mathrm{C}$, but aging at $125{ }^{\circ} \mathrm{C}$ caused a $\mathrm{AgIn}_{2}$ phase to form. Chen et al. also observed variation in the growth kinetics of the ternary Ag-Sn-In phase depending on the composition of the Sn-In phase. ${ }^{[77]}$ Therefore, identifying the diffusion pathway and kinetics for each potential LPDB system of interest will be highly relevant and vital, in addition to the thermodynamic characteristics of the LPDB system, to the success and implementation of future LPDB systems for high temperature solder interconnects.

\section{Conclusions}

The need for new $\mathrm{Pb}$-free solders and high temperature interconnects has continued long after the RoHS-driven, $\mathrm{Pb}$ free solder transition due to demand for both high reliability and good performance in increasingly harsh environments. Alloy thermodynamics and phase diagrams, as represented by the work of Jack Smith, are foundational in our continuing efforts to design $\mathrm{Pb}$-free interconnect solutions with improved performance and for high temperature interfaces. This paper highlights some recent advances in microstructure design for $\mathrm{Pb}$-free interconnect systems, focusing on existing challenges in the nucleation of $\beta-S n$ in Sn-based solder alloys and on alloy design to create isothermally solidified interconnects using transient liquid phases.

The progress made since Swenson's 2007 review of the challenges in $\beta$-Sn nucleation can be understood in the context of Swenson's three approaches for improving $\beta$-Sn nucleation: decreasing, or eliminating, $\mathrm{Ag}$ from Sn-based alloy design to advantage non-equilibrium phase formation, the addition of nucleating heterogeneities to promote $\beta-\mathrm{Sn}$ grain nucleation, and the use of rapid solidification to decrease, or eliminate, primary IMC formation. Despite these advances made based on Swenson's suggestions, a Snbased alloy has yet to be identified that can holistically control solder IMC formation, $\beta$-Sn undercooling, and refinement of $\beta$-Sn grain size (with multiple non-twinned orientations). Thus, future work was proposed via a multifaceted solidification approach combining the benefits of constitutional undercooling with the addition of solute and the effects of heterogeneous nucleating particles to ultimately promote $\beta$-Sn grain refinement in Sn-based solder alloys. Using $\mathrm{Al}$ alloys as the model, growth restriction factors (GRFs) were used to define potential solute additions to pure $\mathrm{Sn}$ that promote constitutional undercooling, and thus enhanced nucleation of the $\beta$-Sn phase. One such suggestion was the addition of $\mathrm{Zn}$ in the range of 3-8 wt.\%
$($ GRFs $=11-29)$, utilized in tandem with uniformly dispersed heterogeneous nucleant particles, such as $\mathrm{XSn}_{4}$ IMCs, which could hold promise for providing both the constitutional undercooling and the potent nucleation sites necessary for enhanced nucleation and ultimate grain refinement the $\beta$-Sn phase. Such a multi-faceted approach to enhancing the nucleation of $\beta$-Sn and thus reducing the overall $\beta$-Sn grain size in Sn-based solder alloys holds much promise and future research, both experimentally and computationally, in these areas of $\beta$-Sn solidification should be pursued.

In the final section, two different approaches to interconnect design were presented based on liquid phase diffusion bonding (LPDB) as a replacement for high- $\mathrm{Pb}$ solders based on the $\mathrm{Cu}-\mathrm{Ni}$-Sn system and on a thermodynamic framework for identifying promising ternary alloys for LPDB. Modification of the equilibrium phases by using $\mathrm{Cu}-\mathrm{Ni}$ alloys as the high melting temperature phase was pursued in order to improve performance previously demonstrated using LPDB systems containing $\mathrm{Cu}-\mathrm{Sn}$ and $\mathrm{Cu}-\mathrm{Ni}$-Sn with separate $\mathrm{Ni}$ and $\mathrm{Cu}$ particles. A framework for selecting alternative LPDB formulations was also described: the equilibrium phase diagrams were used as a starting point for down-selection based on four thermodynamic criteria. This framework was applied to existing data for three Sn-Bi ternaries (Sn-Bi-Ag, Sn-Bi-Cu, and Sn-Bi$\mathrm{Ni}$ ) and three $\mathrm{Sn}-\mathrm{In}$ ternaries $\mathrm{Sn}-\mathrm{In}-\mathrm{Ag}, \mathrm{Sn}-\mathrm{In}-\mathrm{Cu}$, and $\mathrm{Sn}-$ $\mathrm{In}-\mathrm{Ni}$ ), and specific ternaries and composition ranges were identified as promising low temperature phases for LPDB. A special form of metastable diagram for LPDB which we refer to as a "reaction diagram" was introduced as a way to understand the observed deviations from equilibrium phase diagrams for isothermal annealing as a function of temperature and time. Further development of Pb-free solder alloys and LPDB interconnect solutions will continue to build upon the foundations of thermodynamics, to which Jack Smith so significantly contributed throughout his career.

\section{Acknowledgments}

This work was supported by Ames Laboratory, the NSF Cooling Technologies Research Center at Purdue University (NSF I/UCRC Grant IIP 0649702), Nihon Superior through Ames Lab Contract No.DE-AC02-07CH11358, and government support under and awarded by DoD, Air Force Office of Scientific Research, National Defense Science and Engineering Graduate (NDSEG) Fellowship, 32 CFR 168a.

\section{References}

1. J.F. Smith, Thermodynamic Properties of Binary Lithium Systems-A Review, J. Nucl. Mater., 1976, 59(2), p 158-174

2. H.M. Kandil, J.D. Greiner, and J.F. Smith, Single-Crystal Elastic Constants of Yttria-Stabilized Zirconia in the Range 20 to $700{ }^{\circ} \mathrm{C}, \mathrm{J}$. Am. Ceram. Soc., 1984, 67(5), p 341-346

3. C.M. Miller, I.E. Anderson, and J.F. Smith, A Viable Tin-Lead Solder Substitute: Sn-Ag-Cu, J. Electron. Mater., 1994, 23(7), p 595-601 
4. European Parliment, Directive 2012/19/EU of the European Parliment and the Council on Waste Electrical and Electronic Equipment (WEEE) - recast. 2012, pp. 38-71

5. European Parliament, Directive 2011/65/EU of the European Parliment and of the council on the Restriction of the Use of Certain Hazardous Substances in Electrical and Electronic Equipment (RoHS)-recast. 2011, pp. 88-110

6. V. Eveloy, S. Ganesan, Y. Fukuda, J. Wu, and M.G. Pecht, Are You Ready for Lead-Free Electronics?, IEEE Trans. Components Packag. Technol., 2005, 28(4), p 884-894

7. K.J. Puttlitz, Overview of Lead-Free Solder Issues Including Selection, Handbook of Lead-Free Solder Technology for Microelectronic Assemblies, K.J. Puttlitz and K.A. Stalter, Ed., Marcel Decker Inc, New York, 2004, p 3-4

8. D.R. Frear, Issues Related to the Implementation of $\mathrm{Pb}$-free Electronic Solders in Consumer electronics, J. Mater. Sci. Mater. Electron., 2006, 18(1-3), p 319-330

9. K.N. Tu, A.M. Gusak, and M. Li, Physics and Materials Challenges for Lead-Free Solders, J. Appl. Phys., 2003, 93(3), p 1335

10. I. Karakaya and W.T. Thompson, The Pb-Sn (Lead-Tin) system, J. Phase Equilibria, 1988, 9(2), p 144-152

11. K.-W. Moon, W.J. Boettinger, U.R. Kattner, F. Biancaniello, and C.A. Handwerker, Experimental and Thermodynamic Assessment of Sn-Ag-Cu Solder Alloys, J. Electron. Mater, 2000, 29(10), p 1122-1136

12. A. Ohno and T. Motegi, The Effect of Small Additives on the Undercooling of Pure Tin, J. Japan Inst. Met., 1973, 37(7), p 777-780

13. I.E. Anderson, J.C. Foley, B.A. Cook, J. Harringa, R.L. Terpstra, and O. Unal, Alloying Effects in Near-Eutectic SnAg-Cu Solder Alloys for Improved Microstructural Stability, J. Electron. Mater, 2001, 30(9), p 1050-1059

14. K.S. Kim, S.H. Huh, and K. Suganuma, Effects of Fourth Alloying Additive on Microstructures and Tensile Properties of $\mathrm{Sn}-\mathrm{Ag}-\mathrm{Cu}$ Alloy and Joints with $\mathrm{Cu}$, Microelectron. Reliab., 2003, 43(2), p 259-267

15. I.E. Anderson, Development of Sn-Ag-Cu and Sn-Ag-Cu-X Alloys for $\mathrm{Pb}$-free Electronic Solder Applications, J. Mater. Sci. Mater. Electron., 2007, 18(1), p 55-76

16. L.-W. Lin, J.-M. Song, Y.-S. Lai, Y.-T. Chiu, N.-C. Lee, and J.-Y. Uan, Alloying Modification of Sn-Ag-Cu Solders by Manganese and Titanium, Microelectron. Reliab., 2009, 49(3), p 235-241

17. I.E. Anderson, J.W. Walleser, J.L. Harringa, F. Laabs, and A. Kracher, Nucleation Control and Thermal Aging Resistance of Near-Eutectic Sn-Ag-Cu-X Solder Joints by Alloy Design, $J$. Electron. Mater., 2009, 38(12), p 2770-2779

18. A.J. Boesenberg, I.E. Anderson, and J.L. Harringa, Development of Sn-Ag-Cu-X Solders for Electronic Assembly by Micro-Alloying with Al, J. Electron. Mater, 2012, 41(7), p 1868-1881

19. K. Sweatman, T. Nishimura, S. D. McDonald, M. Whitewick, and K. Nogita, Grain Refinement for Improved Lead-Free Solder Joint Reliability, SMT Magazine, pp. 30-40, 2014

20. K.N. Reeve, I.E. Anderson, and C.A. Handwerker, Nucleation and Growth of $\mathrm{Cu}-\mathrm{Al}$ Intermetallics in Al-Modified $\mathrm{Sn}-\mathrm{Cu}$ and $\mathrm{Sn}-\mathrm{Ag}-\mathrm{Cu}$ Lead-Free Solder Alloys, J. Electron. Mater, 2015, 44(3), p 842-866

21. D. Swenson, The Effects of Suppressed Beta Tin Nucleation on the Microstructural Evolution of Lead-Free Solder Joints, $J$. Electron. Mater., 2007, 18(1-3), p 39-54

22. J.H. Perepezko, Nucleation in Undercooled Liquids, Mater. Sci. Eng., 1984, 65(1), p 125-135

23. L.P. Lehman, S.N. Athavale, T.Z. Fullem, A.C. Giamis, R.K. Kinyanjui, M. Lowenstein, K. Mather, R. Patel, D. Rae, J.
Wang, Y. Xing, L. Zavalij, P. Borgesen, and E.J. Cotts, Growth of $\mathrm{Sn}$ and Intermetallic Compounds in $\mathrm{Sn}-\mathrm{Ag}-\mathrm{Cu}$ Solder, $J$. Electron. Mater., 2004, 33(12), p 1429-1439

24. L.P. Lehman, Y. Xing, T.R. Bieler, and E.J. Cotts, Cyclic Twin Nucleation in Tin-based Solder Alloys, Acta Mater., 2010, 58(10), p 3546-3556

25. J.-M. Song, J.-J. Lin, C.-F. Huang, and H.-Y. Chuang, Crystallization, Morphology and Distribution of $\mathrm{Ag}_{3} \mathrm{Sn}$ in $\mathrm{Sn}-\mathrm{Ag}-\mathrm{Cu}$ Alloys and their Influence on the Vibration Fracture Properties, Mater. Sci. Eng. A, 2007, 466(1), p 9-17

26. T.R. Bieler, L.P. Lehman, T. Kirkpatrick, E.J. Cotts, and B. Nandagopal, Influence of Sn Grain Size and Orientation on the Thermomechanical Response and Reliability of $\mathrm{Pb}$-free Solder Joints, IEEE Trans. Components Packag. Technol., 2008, 31(2), p 370-381

27. A.U. Telang and T.R. Bieler, Characterization of Microstructure and Crystal Orientation of the Tin Phase in Single Shear Lap Sn-3.5Ag Solder Joint Specimens, Scr. Mater., 2005, 52(10), p 1027-1031

28. K.L. Buckmaster, J.J. Dziedzic, M.A. Masters, B.D. Poquette, G.W. Tormoen, D. Swenson, D.W. Henderson, T. Gosselin, S.K. Kang, D.Y. Shih, and K.J. Puttlitz, The Effects of Minor $\mathrm{Zn}$ Alloying Additions on the Solidification Behavior and Microstructure of Near-Eutectic Sn-Ag-Cu Solder Joints, in Presented at the "Pb-Free and Pb-Bearing Solders: Solidification” Symposium at the Materials Science \& Technology (MS\&T) Conference 2003 Fall Meeting

29. S.K. Kang, D.Y. Shih, D. Leonard, D.W. Henderson, T. Gosselin, S. Cho, J. Yu, and W.K. Choi, Controlling Ag3Sn Plate Formation in Near-Ternary-Eutectic $\mathrm{Sn}-\mathrm{Ag}-\mathrm{Cu}$ Solder by Minor Zn Alloying, J. Met., 2004, 56(6), p 34-38

30. K.S. Kim, S.H. Huh, and K. Suganuma, Effects of Cooling Speed on Microstructure and Tensile Properties of Sn-Ag-Cu Alloys, Mater. Sci. Eng. A, 2002, 333(1-2), p 106-114

31. D.W. Henderson, T. Gosselin, A. Sarkhel, S.K. Kang, W. Choi, D. Shih, C. Goldsmith, and K.J. Puttlitz, $\mathrm{Ag}_{3} \mathrm{Sn}$ Plate Formation in the Solidification of Near Ternary Eutectic SnAg-Cu Alloys, J. Mater. Res., 2002, 17(11), p 2775-2778

32. D. Suh, D.W. Kim, P. Liu, H. Kim, J.A. Weninger, C.M. Kumar, A. Prasad, B.W. Grimsley, and H.B. Tejada, Effects of $\mathrm{Ag}$ Content on Fracture Resistance of $\mathrm{Sn}-\mathrm{Ag}-\mathrm{Cu}$ Lead-Free Solders under High-Strain Rate Conditions, Mater. Sci. Eng. A, 2007, 460-461(July), p 595-603

33. H. Tsukamoto, T. Nishimura, S. Suenaga, S.D. Mcdonald, K.W. Sweatman, and K. Nogita, The Influence of Solder Composition on the Impact Strength of Lead-Free Solder Ball Grid Array Joints, Microelectron. Reliab., 2011, 51(3), p 657-667

34. C.E. Ho, R.Y. Tsai, Y.L. Lin, and C.R. Kao, Effect of $\mathrm{Cu}$ Concentration on the Reactions between $\mathrm{Sn}-\mathrm{Ag}-\mathrm{Cu}$ Solders and Ni, J. Electron. Mater., 2002, 31(6), p 584-590

35. C.W. Chang, S.C. Yang, C.-T. Tu, and C.R. Kao, CrossInteraction between $\mathrm{Ni}$ and $\mathrm{Cu}$ across $\mathrm{Sn}$ Layers with Different Thickness, J. Electron. Mater., 2007, 36(11), p 1455-1461

36. W.M. Chen, T.L. Yang, C.K. Chung, and C.R. Kao, The Orientation Relationship between $\mathrm{Ni}$ and $\mathrm{Cu} 6 \mathrm{Sn} 5$ Formed during the Soldering Reaction, Scr. Mater., 2011, 65(4), p 331-334

37. K. Nogita and T. Nishimura, Nickel-Stabilized Hexagonal $(\mathrm{Cu}$, $\mathrm{Ni}$ 6Sn5 in Sn-Cu-Ni Lead-free Solder Alloys, Scr. Mater., 2008, 59(2), p 191-194

38. K. Nogita, C.M. Gourlay, and T. Nishimura, Cracking and Phase Stability in Reaction Layers between $\mathrm{Sn}-\mathrm{Cu}-\mathrm{Ni}$ Solders and $\mathrm{Cu}$ Substrates, J. Mater., 2009, 61(6), p 45-51

39. K. Nogita, Stabilisation of $\mathrm{Cu}_{6} \mathrm{Sn}_{5}$ by Ni in $\mathrm{Sn}-0.7 \mathrm{Cu}-0.05 \mathrm{Ni}$ Lead-free Solder Alloys, Intermetallics, 2010, 18(1), p 145149 
40. K. Nogita, D. Mu, S.D. Mcdonald, J. Read, and Y.Q. Wu, Effect of Ni on Phase Stability and Thermal Expansion of $\mathrm{Cu}(6-\mathrm{x}) \mathrm{Ni}(\mathrm{x}) \operatorname{Sn} 5(\mathrm{X}=0,0.5,1,1.5$ and 2$)$, Intermetallics, 2012, 26(July), p 78-85

41. J.W. Xian, S.A. Belyakov, T.B. Britton, and C.M. Gourlay, Heterogeneous Nucleation of Cu6Sn5 in $\mathrm{Sn}-\mathrm{Cu}-\mathrm{Al}$ Solders, $J$. Alloys Compd., 2015, 619(January), p 345-355

42. J.W. Xian, S.A. Belyakov, and C.M. Gourlay, Controlling Bulk Cu6Sn5 Nucleation in $\mathrm{Sn} 0.7 \mathrm{Cu} / \mathrm{Cu}$ Joints with Al Microalloying, J. Electron. Mater, 2015, 45(1), p 69-78

43. K. N. Reeve, S. M. Choquette, I. E. Anderson, and C. A. Handwerker, Rapid Solidification of Micro-Alloyed Sn-Cu-Al Alloys for High Reliability Lead-Free Solder: Part I. Microstructural Characterization of Rapidly Solidified Solders, Metall. Mater. Trans. A, (accepted), March 2016

44. K. N. Reeve, S. M. Choquette, I. E. Anderson, and C. A. Handwerker, Rapid Solidification of Micro-Alloyed Sn-Cu-Al Alloys for High Reliability Lead-Free Solder: Part II. Intermetallic Coarsening Behavior of Rapidly Solidified Solders after Multiple Reflows, Metall. Mater. Trans. A, (under review), March 2016

45. S.A. Belyakov and C.M. Gourlay, Heterogeneous Nucleation of $\beta \mathrm{Sn}$ on NiSn4, PdSn4 and PtSn4, Acta Mater, 2014, 71(June), p 56-68

46. W.C. Winegard, S. Majka, B.M. Thall, and B. Chalmers, Eutectic Solidification in Metals, Can. J. Chem., 1951, 29(4), p 320-327

47. W.A. Tiller, K.A. Jackson, J.W. Rutter, and B. Chalmers, The Redistribution of Solute Atoms during Solidification of Metals, Acta Metall., 1953, 1(4), p 428-437

48. J. Lipton, M.E. Glicksman, and W. Kurz, Dendritic Growth into Undercooled Alloy Melts, Mater. Sci. Eng., 1984, 65(1), p 57-63

49. D.H. Kirkwood, Microsegregation, Mater. Sci. Eng., 1984, 65(1), p 101-109

50. J. Lipton, W. Kurz, and R. Trivedi, Rapid Dendrite Growth in Undercooled Alloys, Acta Metall., 1987, 35(4), p 957-964

51. M.A. Chopra, M.E. Glicksman, and N.B. Singh, Dendritic Solidification in Binary Alloys, Metall. Trans. A, 1988, 19(12), p 3087-3096

52. D.H. StJohn, A. Prasad, M.A. Easton, and M. Qian, The Contribution of Constitutional Supercooling to Nucleation and Grain Formation, Metall. Mater. Trans. A, 2015, 46(11), p 4868-4885

53. M. Easton and D. StJohn, Grain Refinement of Aluminum Alloys : Part I. The Nucleant and Solute Paradigms - A Review of the Literature, Metall. Mater. Trans. A, 1999, 30(6), p 1613-1623

54. M. Easton and D. StJohn, Grain Refinement of Aluminum Alloys : Part II. Confirmation of, and a Mechanism for the Solute Paradigm, Metall. Mater. Trans. A, 1999, 30(6), p 1625-1633

55. M. Easton and D. StJohn, A Model of Grain Refinement Incorporating Alloy Constitution and Potency of Heterogeneous Nucleant Particles, Acta Mater., 2001, 49(10), p 18671878

56. M. Easton and D. StJohn, An Analysis of the Relationship between Grain Size, Solute Content, and the Potency and Number Density of Nucleant Particles, Metall. Mater. Trans. $A$, 2005, 36(7), p 1911-1920

57. Thermo-Calc Software - version 3. Solder databases versions 1 (TCSLD1) and 3 (TCSLD3). http://www.thermocalc.com/ products-services/software/thermo-calc/. Accessed $13 \mathrm{Apr}$ 2016
58. K. Suganuma, S.-J. Kim, and K.-S. Kim, High-Temperature Lead-Free Solders: Properties and Possibilities, J. Met., 2009, 61(1), p 64-71

59. S. Kim, K.-S. Kim, K. Suganuma, and G. Izuta, Interfacial Reactions of Si Die Attachment with $\mathrm{Zn}-\mathrm{Sn}$ and Au-20Sn High Temperature Lead-Free Solders on $\mathrm{Cu}$ Substrates, J. Electron. Mater., 2009, 38(6), p 873-883

60. J. Harris and M. Matthews, Selecting Die Attach Technology for High-Power Applications, Power Electronics. http://powe relectronics.com/dc-dc-converters/selecting-die-attach-technolo gy-high-power-applications, accessed 25 Mar 2016

61. V. Chidambaram, H.B. Yeung, and G. Shan, Reliability of Au$\mathrm{Ge}$ and $\mathrm{Au}-\mathrm{Si}$ Eutectic Solder Alloys for High-Temperature Electronics, J. Electron. Mater., 2012, 41(8), p 2107-2117

62. G. Zeng, S. McDonald, and K. Nogita, Development of HighTemperature Solders: Review, Microelectron. Reliab., 2012, 52(7), p 1306-1322

63. Z.X. Zhu, C.C. Li, L.L. Liao, C.K. Liu, and C.R. Kao, Au-Sn Bonding Material for the Assembly of Power Integrated Circuit Module, J. Alloys Compd., 2016, 671(June), p 340-345

64. K. Sweatman, T. Nishimura, and T. Komatsu, A Nano Silver Replacement for High Lead Solders in Semiconductor Junctions, J. Surf. Mount Technol., 2013, 26(2), p 21-27

65. S.J. Kim, E.A. Stach, and C.A. Handwerker, Fabrication of Conductive Interconnects by $\mathrm{Ag}$ Migration in $\mathrm{Cu}-\mathrm{Ag}$ CoreShell Nanoparticles, Appl. Phys. Lett., 2010, 96(14), p 144101-1-144101-3

66. H. Zhang and N. Lee, Reliability of BiAgX as a Drop-in Solution for High Temperature Lead-Free Die-Attach Applications, J. Surf. Mount Technol., pp. 28-32, 2013

67. P. McCluskey and H. Greve, Transient Liquid Phase Sintered Joints for Wide Bandgap Power Electronics Packaging, in Pan Pacific Conference Proceedings, 2014, pp. 1-10

68. S.A. Moeini, H. Greve, and P. McCluskey, Reliability and Failure Analysis of Cu-Sn Transient Liquid Phase Sintered (TLPS) Joints under Power Cycling Loads, in IEEE 3rd Workshop on Wide Bandgap Power Devices and Applications, 2015, pp. 383-389

69. S.M. Choquette and I.E. Anderson, Liquid-Phase Diffusion Bonding: Temperature Effects and Solute Redistribution in High-Temperature Lead-Free Composite Solders, Int. J. Powder Metall., 2015, 51(4), p 1-10

70. V. R. Manikam and K. Y. Cheong, Die Attach Materials for High Temperature Applications: A Review, in IEEE Transactions on Components, Packaging, and Manufacturing Technology, vol. 1, no. 4, pp. 457-478, 2011

71. A.H.M.E. Rahman and M.N. Cavalli, Diffusion Bonding of Commercially Pure Ni using $\mathrm{Cu}$ Interlayer, Mater. Charact., 2012, 69(July), p 90-96

72. H. Greve, L.-Y. Chen, I. Fox, and F. P. McCluskey, Transient Liquid Phase Sintered Attach for Power Electronics, in 2013 Electronic Components and Technology Conference, 2013, pp. 435-440

73. H. Greve and P. Mccluskey, Reliability of Sn based LT-TLPS Joints for High Temperature Electronic Systems, in Integrated Power Systems (CIPS), 2014, pp. 25-27

74. V. Vuorinen, H. Yu, T. Laurila, and J.K. Kivilahti, Formation of Intermetallic Compounds between Liquid $\mathrm{Sn}$ and Various CuNix Metallizations, J. Electron. Mater., 2008, 37(6), p 792805

75. V.A. Baheti, S. Islam, P. Kumar, R. Ravi, R. Narayanan, D. Hongqun, V. Vuorinen, T. Laurila, and A. Paul, Effect of Ni Content on the Diffusion-Controlled Growth of the Product 
Phases in the Cu(Ni)-Sn System, Philos. Mag., 2016, 96(1), p 15-30

76. C.-H. Lin, S.-W. Chen, and C.-H. Wang, Phase Equilibria and Solidification Properties of Sn-Cu-Ni Alloys, J. Electron. Mater., 2002, 31(9), p 907-915

77. S. Chen, W. Lee, C. Hsu, C. Yang, H. Hsu, and H. Wu, Sn-InAg Phase Equilibria and Sn-In-(Ag)/Ag Interfacial Reactions, Mater. Chem. Phys., 2011, 128(3), p 357-364

78. S.-W. Cheng, C.-H. Wang, S.-K. Lin, and C.-N. Chiu, Phase Diagrams of $\mathrm{Pb}$-Free Solders and their Related Materials Systems, J. Mater. Sci. Mater. Electron., 2007, 18(1), p 19-37
79. G. Vassilev, N. Milchevaa, M.C. Record, and R. Mancheva, Diffusion Couple Studies of the Ni-Bi-Sn System, J. Min. Metall. Sect. B, 2012, 48(3), p 347-357

80. National Insitute of Standards and Technology, Phase Diagram \& Computational Thermodynamics: Bi-Cu-Sn System, Materials Science and Engineering Division - National Institute of Standards and Technology (NIST). http://www.metallurgy.nist. gov/phase/solder/bicusn.html, accessed 19 May 2016

81. W.A. Sasangka, C.L. Gan, C.V. Thompson, W.K. Choi, and J. Wei, Influence of Bonding Parameters on the Interaction between $\mathrm{Cu}$ and Noneutectic Sn-In Solder Thin Films, J. Electron. Mater., 2011, 40(11), p 2329-2336 